\title{
Pyrrolidine in Drug Discovery: A Versatile Scaffold for Novel Biologically Active Compounds
}

\author{
Giovanna Li Petri ${ }^{1} \cdot$ Maria Valeria Raimondi ${ }^{1}$ (D) - Virginia Spanò ${ }^{1} \cdot$ Ralph Holl $^{2}$. \\ Paola Barraja $^{1} \cdot$ Alessandra Montalbano $^{1}$
}

Received: 2 April 2021 / Accepted: 25 July 2021 / Published online: 10 August 2021

(c) The Author(s) 2021

\begin{abstract}
The five-membered pyrrolidine ring is one of the nitrogen heterocycles used widely by medicinal chemists to obtain compounds for the treatment of human diseases. The great interest in this saturated scaffold is enhanced by (1) the possibility to efficiently explore the pharmacophore space due to $\mathrm{sp}^{3}$-hybridization, (2) the contribution to the stereochemistry of the molecule, (3) and the increased three-dimensional (3D) coverage due to the non-planarity of the ring-a phenomenon called "pseudorotation". In this review, we report bioactive molecules with target selectivity characterized by the pyrrolidine ring and its derivatives, including pyrrolizines, pyrrolidine-2-one, pyrrolidine-2,5-diones and prolinol described in the literature from 2015 to date. After a comparison of the physicochemical parameters of pyrrolidine with the parent aromatic pyrrole and cyclopentane, we investigate the influence of steric factors on biological activity, also describing the structure-activity relationship (SAR) of the studied compounds. To aid the reader's approach to reading the manuscript, we have planned the review on the basis of the synthetic strategies used: (1) ring construction from different cyclic or acyclic precursors, reporting the synthesis and the reaction conditions, or (2) functionalization of preformed pyrrolidine rings, e.g., proline derivatives. Since one of the most significant features of the pyrrolidine ring is the stereogenicity of carbons, we highlight how the different stereoisomers and the spatial orientation of substituents can lead to a different biological profile of drug candidates, due to the different binding mode to enantioselective proteins. We believe that this work can guide medicinal chemists to the best approach in the design of new pyrrolidine compounds with different biological profiles.
\end{abstract}

Keywords Pyrrolidine $\cdot$ Anticancer and antibacterial agents $\cdot$ Central nervous system diseases $\cdot$ Antidiabetics $\cdot$ Anti-inflammatory and analgesic agents

Maria Valeria Raimondi

mariavaleria.raimondi@unipa.it

Extended author information available on the last page of the article 


\section{Abbreviations}

5-LOX

A549

AChE

AD

AG

ALR2

APP

AR

ATX

AZA

$\mathrm{A} \beta$

BACE1

BBB

BChE

BHK

CAPAN-1

Cas

$\mathrm{CC}_{50}$

CCRF-CEM

$\mathrm{CNS}$

COX-1

DHFR

$\mathrm{DNJ} \cdot \mathrm{HCl}$

DOS

DPP4

$\alpha / \gamma \mathrm{EC}_{50}$

$\mathrm{ED}_{50}$

ER

ER

ES-2

FAAH

FDA

FPA

FTase

$\mathrm{GI}_{50}$

Glc-N-6P

GLP-1

GlyT1

hCA I and II

HDAC2

$\mathrm{HeLa}$

hGLYT1

$\mathrm{IC}_{50}$

K562

KIT
5-Lipoxygenase

Lung cancer cell line

Acetylcholinesterase

Alzheimer's disease

$\alpha$-Glucosidase

Aldose reductase

Amyloid precursor protein

Androgen receptor

Autotaxin

Acetazolamide

Amyloid- $\beta$

Beta-secretase 1

Blood-brain barrier

Butyrylcholinesterase

Baby hamster kidney cell line

Pancreatic cancer cell line

Carbonic anhydrases

Concentration required to inhibit cell proliferation by $50 \%$

Acute lymphocytic leukemia

Central nervous system

COX-2, cyclooxygenase-1, cyclooxygenase-2

Dihydrofolate reductase

Deoxynojirimycin chlorohydrate

Diversity-oriented synthesis

Dipeptidyl peptidase-4

$\alpha / \gamma$ Half maximal effective concentration values

Median effective dose

Efflux ratio

Estrogen receptor

Ovarian clear carcinoma cell

Fatty acid amide hydrolase

Food and Drug Administration

Fluorescence polarization assay

Human protein farnesyltransferase

Growth inhibitory dose $50 \%$

Glucosamine-6-phospate synthase

Glucagon-like peptide-1

Glycine transporter-1

Human isoenzymes I and II

Histone deacetylase 2

Cervix carcinoma

Human glycine transporter-1

Half maximal inhibitory concentration value

Chronic myeloid leukaemia cell line

Tyrosine-protein kinase KIT 


$\begin{array}{ll}\text { MBH } & \text { Morita-Baylis-Hillman } \\ \text { Mcl-1 } & \text { Myeloid cell leukemia-1 } \\ \text { MCF-7 } & \text { Breast cancer cell line } \\ \text { MDA-MB-436 } & \text { Breast carcinoma cell line } \\ \text { MES } & \text { Maximal electroshock } \\ \text { MMP-2 } & \text {-9, Matrix metalloproteinases 2, -9 } \\ \text { NAAA } & \text { N-Acylethanolamine acid amidase } \\ \text { NBS } & \text { N-Bromosuccinimide } \\ \text { NCI } & \text { National Cancer Institute } \\ \text { NCI-H522 } & \text { Non-small cell lung cancer } \\ \text { NMDA } & \text { N-Methyl-D-aspartate } \\ \text { NP } & \text { Natural product } \\ \text { PARP-1-2 } & \text { Poly(ADP-ribose) polymerase-1, -2 } \\ \text { PXR } & \text { Pregnane X receptor } \\ \text { PC-3 } & \text { Prostatic cancer cell line } \\ \text { PDB ID } & \text { Protein data bank identification } \\ \text { P-gp } & \text { P-glycoprotein } \\ \text { PHB2 } & \text { Prohibitin 2 } \\ \text { PK } & \text { Pharmacokinetics } \\ \text { PPARs } & \text { Peroxisome proliferator-activated receptors } \\ \text { P-tau } & \text { Tau protein } \\ \text { ROR } \gamma t & \text { Retinoic acid-related orphan receptor } \gamma \\ \text { SAR } & \text { Structure-activity relationship } \\ \text { SARMs } & \text { Selective androgen receptor modulators } \\ \text { scPTZ } & \text { Subcutaneous pentylenetetrazole } \\ \text { SI } & \text { Selectivity index } \\ \text { VDCCs } & \text { Voltage-gated calcium channels } \\ \text { VGSCs } & \text { Voltage-gated sodium channels } \\ \text { VPA } & \text { Valproic acid } \\ & \end{array}$

\section{Introduction}

The development of clinically active drugs relies increasingly on the use of heterocyclic scaffolds, many of which contain nitrogen, as evidenced by the considerable number of bioactive compounds now available [1-5]. The introduction of heteroatomic fragments in these molecules is not a random choice, considering that they are useful tools for modifying physicochemical parameters and obtaining the best ADME/Tox results for drug candidates [6, 7]. Although two-dimensional (2D) flat heteroaromatic ring scaffolds are used widely by medicinal chemists, due mainly to their easy structural modification [8, 9], heteroatomic saturated ring systems allow a greater chance of generating structural diversity [10]. This molecular complexity was defined by Lovering et al. [11] through two descriptors, the $\mathrm{sp}^{3}$-hybridization and number of chiral centers, both of which are essential for establishing the clinical success of new bioactive molecules. Indeed, the chemical complexity and the globular three-dimensional (3D) shape offer more opportunities to improve druggability 
by modifying parameters such as solubility, lipophilicity, and other ADME properties [12]. This association was also highlighted by Ritchie et al. [13] who conducted an interesting study on a set of 19,196 molecules containing three rings with different degrees of aromaticity. Molecules with growing hetero-aliphatic character showed an increase in aqueous solubility compared with those comprising three aromatic rings. Thus, each portion of the molecules can potentially influence the balance of the physicochemical parameters, which needs to be considered when designing compounds with an optimized pharmacokinetic (PK) profile. Table 1 summarizes a comparison of some of the molecular descriptors and parameters of the pyrrolidine nucleus with that of carbocyclic cyclopentane and aromatic pyrrole. As shown in Table 1, the presence of the nitrogen atom contributes to the polarity of the molecules, producing a dipole moment $(D)$ and a marked PSA value, which cyclopentane lacks. Although both, pyrrole and pyrrolidine, show similar polar surface area (PSA) values, only the $\mathrm{pK}_{\mathrm{BHX}}$ values (pyrrole $=0.15$, pyrrolidine $=2.59$ ) take into account the strength of the H-bonds. The presence of nitrogen also affects the lipophilicity of the heterocyclic rings, as evidenced by the lower LogP values of pyrrolidine and pyrrole, and the solvent accessible surface area (SASA) FISA and FOSA values. Also interesting is the CI_logS value of pyrrole, which is different from the $\log S$, highlighting how the planarity of the aromatic ring can influence aqueous solubility.

Over the past two decades, much effort have been made by industry to provide the chemistry community with new $\mathrm{sp}^{3}$-enriched 3D building blocks as commercial sources from which to produce molecules relevant from a medicinal chemistry point of view. In this context, Goldberg et al. [14] from AstraZeneca shed light on "design guidelines and strategic goals when designing novel reagents for drug discovery projects", and the 3D shape appears as one of the strategic goals for the design of reagents for drug discovery programs. The 3D shapes of the non-aromatic pyrrolidine and cyclopentane rings with the aromatic pyrrole ring are compared in Fig. 1. The different bond angles and lengths clearly suggest the flatness of the 2D structure of pyrrole and the 3D coverage of pyrrolidine and cyclopentane.

A statistical analysis conducted by Tajabadi et al. [15] found that $70 \%$ of the 15,822 scaffolds belonging to natural products (NPs) are non-flat and represent an interesting resource for the design of new synthetic molecules [16]. Among such saturated ring systems, the pyrrolidine moiety is represented widely in NPs, especially in alkaloids isolated from plants or microorganisms [17-19] (Fig. 2) showing different biological activities, e.g. nicotine 1 (antioxidant, anti-inflammatory, antihyperglycemic properties), scalusamides A $\mathbf{2}$ and (R)-bgugaine $\mathbf{3}$ (antimicrobial, antifungal properties), 1,4-dideoxy-1,4-imino-D-ribitol $\mathbf{4}$ and aegyptolidine A $\mathbf{5}$ (anticancer properties). Therefore, it is no coincidence that the pyrrolidine nucleus is among the most preferred scaffolds in pharmaceutical science and drug design [20], as evidenced by the fact that it ranks first among the top five most common fivemembered non-aromatic nitrogen heterocycles, appearing in 37 drugs approved by the United States (US) Food and Drug Administration (FDA) [21]. Moreover, pyrrolidine and its derivatives are used widely as ligands for transition metals, organocatalysts, and effective chiral controllers in asymmetric synthesis [22-24]. 


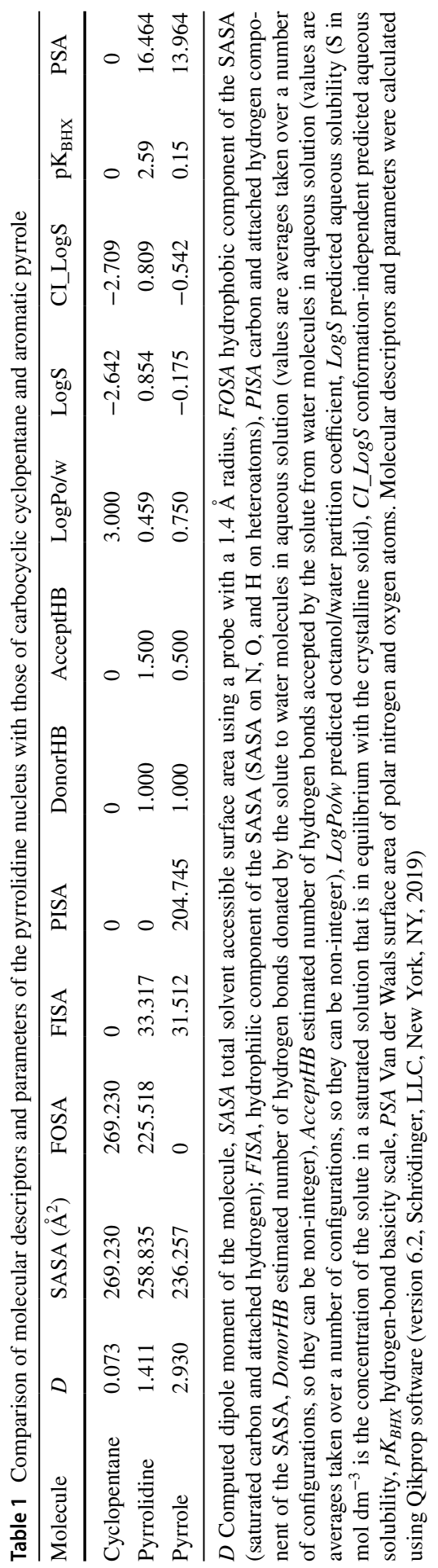




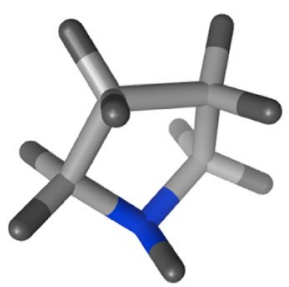

MMFF94 $0.647 \mathrm{kcal} / \mathrm{mol}$

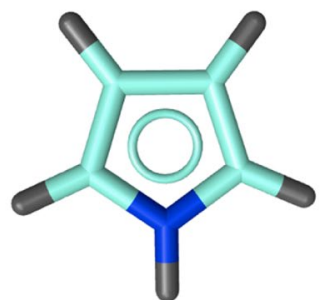

MMFF94 $3.287 \mathrm{kcal} / \mathrm{mol}$

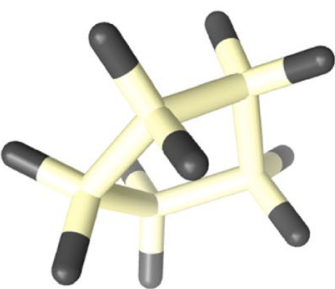

MMFF94 $1.549 \mathrm{kcal} / \mathrm{mol}$

\begin{tabular}{|c|c|c|c|}
\hline & Pyrrolidine & Pyrrole & Cyclopentane \\
\hline & \multicolumn{3}{|c|}{ Bond Length $(\AA)$} \\
\hline $\mathrm{N}(1)-\mathrm{C}(2)$ & 1.47 & 1.37 & - \\
\hline $\mathrm{C}(1)-\mathrm{C}(2)$ & - & - & 1.53 \\
\hline$C(2)-C(3)$ & 1.51 & 1.38 & 1.52 \\
\hline$C(3)-C(4)$ & 1.51 & 1.42 & 1.52 \\
\hline$C(4)-C(5)$ & 1.52 & 1.38 & 1.52 \\
\hline $\mathrm{C}(5)-\mathrm{N}(1)$ & 1.47 & 1.37 & - \\
\hline \multirow[t]{2}{*}{$C(5)-C(1)$} & - & - & 1.53 \\
\hline & \multicolumn{3}{|c|}{ Bond Angle $(\AA)$} \\
\hline$C(2)-N(1)-C(5)$ & 107.63 & 109.33 & - \\
\hline$C(2)-C(1)-C(5)$ & - & - & 103.63 \\
\hline $\mathrm{N}(1)-\mathbf{C}(2)-\mathrm{C}(3)$ & 105.54 & 108.00 & - \\
\hline$C(1)-C(2)-C(3)$ & - & - & 105.74 \\
\hline$C(2)-\mathbf{C}(3)-C(4)$ & 102.26 & 107.34 & 106.30 \\
\hline$C(3)-C(4)-C(5)$ & 103.13 & 107.33 & 104.90 \\
\hline $\mathrm{C}(4)-\mathrm{C}(\mathbf{5})-\mathrm{N}(1)$ & 106.83 & 108.00 & - \\
\hline$C(4)-C(5)-C(1)$ & - & - & 102.95 \\
\hline
\end{tabular}

Fig. 1 Comparison of the three-dimensional (3D) shape of the non-aromatic pyrrolidine and cyclopentane rings with the aromatic pyrrole ring. Bond angles, bond lengths, and MMFF94 values were calculated using LigandScout software version 4.4 Expert<smiles>CN1CCCC1c1cccnc1</smiles>

1

(S)-Nicotine (from tabacco)<smiles>C/C=C/CCCCC(=O)CC(=O)N1CCC[C@H]1CO</smiles>

Scalusamides A

(from the cultured broth of Penicillium citrinum)<smiles>CCCCCC1CCCN1C</smiles>

3

(R)-bgugaine (from Arisarum vulgare)<smiles>CN1C[C@](C)(O)[C@@](C)(O)[C@H]1CO</smiles>

\section{4}

1,4-dideoxy-1,4-imino-D-ribitol (from the Morus alba)<smiles>CC(=O)OC[C@H]1NC(=O)[C@H](Cl)[C@@H]1Oc1ccc(O)cc1</smiles>

Aegyptolidine A

(from Aspergillus aegyptiacus)

Fig. 2 Representative structures of natural alkaloids 1-5 
The great interest in the pyrrolidine scaffold has allowed chemists to explore new methods for its synthesis, thus bypassing conventional approaches. The application of microwave-assisted organic synthesis (MAOS) for the synthesis of pyrrolidines has had a strong impact, allowing synthetic efficiency to be increased, and also supporting the new era of green chemistry [25].

In this review, we highlight the interest of the chemistry community in pyrrolidine and its derivatives, including pyrrolizines, pyrrolidine-2-one, pyrrolidine2,5-diones, and prolinol, incorporated in bioactive molecules with target selectivity published from 2015 to date. We have organized the review on the basis of the synthetic approach used: (1) construction of the ring from different cyclic or acyclic precursors, and (2) functionalization of preformed pyrrolidine rings, e.g., proline derivatives.

\section{Influence of Steric Factors on Biological Activity}

Contrary to the parent aromatic compound pyrrole, which is a common scaffold of several bioactive compounds [26-28], the great interest in synthetic pyrrolidines is also due to the presence of up to four stereogenic carbon atoms leading to up to 16 different stereoisomers [29]. In this regard, the non-essential amino acid L-proline, with one chiral center, is frequently employed as a building block to produce chiral compounds, and as a catalyst for successful stereoselective synthesis [30, 31]. Since proteins are enantioselective, the introduction of chiral centers would represent a purposive strategy for the generation of selective ligands. Moreover, knowing the absolute and relative configuration of chiral centers can allow the toxicity or inactivity of one of the enantiomers to be avoided, a concept regulated extensively by US FDA guidelines on the "Development of new stereoisomeric drugs" [32]. In contrast to the pyrrole ring, thanks to "pseudorotation", an intrinsic property of saturated five-membered rings, pyrrolidines gain energetically advantageous conformations offering interesting 3D coverings [33] — a useful tool for the exploration of pharmacophore space via diversity-oriented synthesis (DOS) [34, 35]. Overall, based on the electronegativity of $\mathrm{C}-4$ substituents, the pyrrolidine ring of proline acquires two specific conformations called C-4 (or $\mathrm{C} \gamma$ ) -exo and -endo envelope conformers. This means that puckering of the ring can be controlled easily through inductive

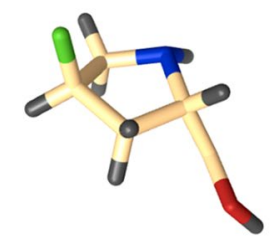

trans-4-fluoroproline 6

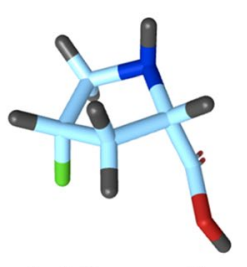

cis-4-fluoroproline 7

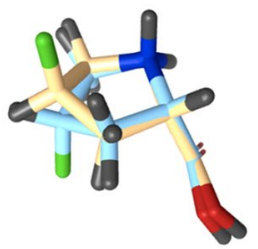

Overlap trans/cis-4-fluoroproline 8

Fig. 3 Exo and endo conformers of trans- and cis-4-fluoroproline 6 and 7, respectively; trans/cis-4-fluoroproline 8 resulting from the superimposition of structures 6 and 7 
and stereoelectronic factors. For instance, in the case of L-proline, the endo conformer is preferred, whereas trans-4-fluoroproline 6 and cis-4-fluoroproline 7 favor the exo and endo envelope conformation, respectively (Fig. 3). The overlap of trans/ cis-4-fluoroproline 8 clearly shows the different folding of the molecules induced by the $R$ or $S$ configuration of the carbon bearing the fluorine atom. Conversely, C-4 alkylation of proline with a methyl or tert-butyl group is used to lock the opposite conformation [36].

\subsection{The Enantiopure Compound Shows Full Agonism Towards G-Protein Coupled Receptor 40}

Notably, Jurica et al. [37] synthesized a series of G-protein coupled receptor 40 (GRP40) agonists, like compounds $(R, R)-\mathbf{9}$ and $(S, S)-\mathbf{9}$, for the treatment of type 2 diabetes (Fig. 4). They demonstrated that a cis-4-CF 3 substituent on the pyrrolidine scaffold favors the pseudo-axial conformation of the groups in the other positions, as evaluated for the acetic acid group at position 2, which is the main pharmacophore for GRP40 agonists. By lead optimization, they observed that the enantiopure $(R, R)$ 9 derivative displayed full agonism, both in human GRP40 (hGRP40, $0.11 \mu \mathrm{M}$ ) and mouse GRP40 (mGRP40, $0.054 \mu \mathrm{M})$ due to the different binding mode compared to its enantiomer $(S, S)$-9 (hGRP40 $0.49 \mu \mathrm{M}$ and mGRP40 $2.4 \mu \mathrm{M}$ ), in addition to a better in vivo profile in lowering glucose plasma levels in mice tested in the oral glucose tolerance test at 0.3 or $1 \mathrm{mg} \mathrm{kg}^{-1}$ doses, and a dual mechanism of action including glucose-dependent insulin and GLP-1 secretion in vitro.

\subsection{The New Spatial Arrangement in the Crystallized Ligand-Protein Complex Promotes Selectivity for CK1Y}

The role of steric factors was also investigated by Luxenburger et al. [38], who synthesized potent and selective CK1 kinase inhibitors exhibiting a chiral pyrrolidine scaffold, functionalizing the CK1 $\gamma$ inhibitor derivative 10 (Fig. 4). Interestingly, the new enantiopure hydroxyl-functionalized pyrrolidine derivatives 11a-b (Fig. 4) showed selectivity for CK1 in the enzyme assay against a panel of 320 different kinases. To investigate the binding mode of the chiral moiety, X-ray crystallography was conducted. The crystal structure showed that, due to the incorporation of a methylene group through a spontaneously Pictet-Spengler cyclization, two new ligands (compounds 12a,b) (Fig. 4) were formed. These compounds showed nanomolar activity against CK $1 \gamma$ and CK $1 \varepsilon(0.011$ and $0.056 \mu \mathrm{M}$, and 0.024 and $0.196 \mu \mathrm{M}$, respectively), thus suggesting that further modifications should be made to investigate how the chiral moiety influences kinase inhibition.

\subsection{The Orientation of 3-R-Methylpyrrolidine is Responsible for a Pure Estrogen Receptor a Antagonist and Selective ER Degrader}

In 2018, through biochemical and biophysical assays, coupled with high-resolution X-ray crystal structures, Fanning et al. [39] provided a molecular explanation of how 
<smiles>COc1ccc(F)c(-c2ccc(Cc3ccc(N4C[C@H](C(F)(F)F)C[C@H]4CC(=O)O)cc3C)cc2)c1</smiles>

$(S, S)-9$

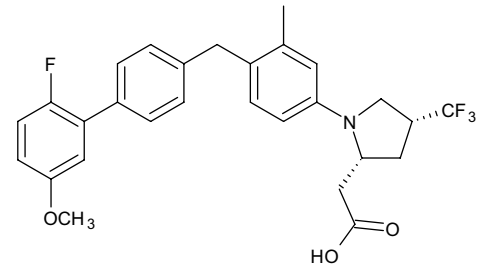

$(\boldsymbol{R}, \boldsymbol{R})-9$

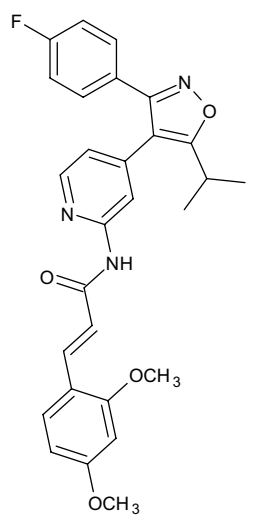

10<smiles>[R]C(=O)Nc1cc(-c2c(-c3ccc(F)cc3)noc2C(C)C)ccn1</smiles>

$12 a, b$<smiles>[R]COc1ccc(C2Oc3cc(O)ccc3C(C)=C2c2ccc(O)cc2)cc1</smiles>

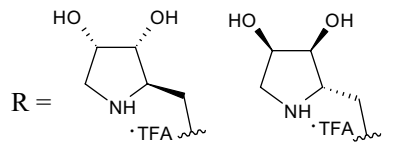

$11 \mathrm{a}$

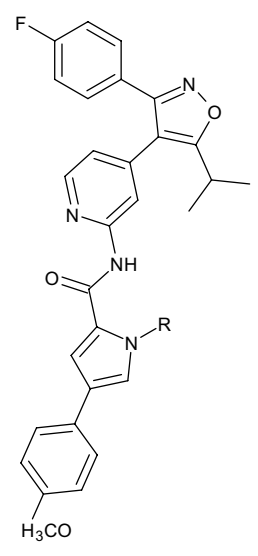

11a,b

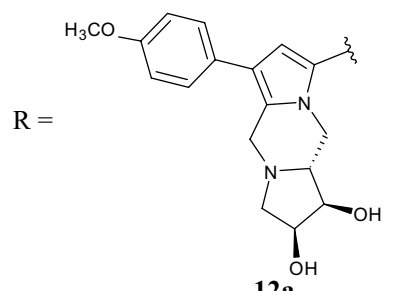

$12 \mathbf{a}$

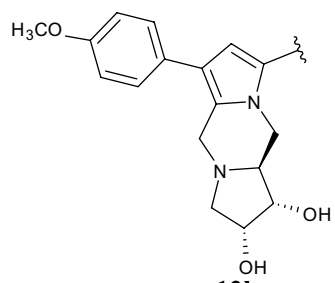

$12 b$
$\mathrm{R}=$<smiles>CCN1CCC(C)C1</smiles>

$13 a$

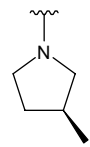

13b

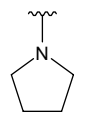

14

Fig. 4 Stereospecific pyrrolidine derivatives $(R, R)-\mathbf{9},(S, S)-\mathbf{9}, \mathbf{1 1 a}, \mathbf{b}, \mathbf{1 2 a}, \mathbf{b}, \mathbf{1 3 a}, \mathbf{b}$, and 14 
the stereospecific orientation can change the binding mode of antiestrogen benzopyran derivatives 13a,b and $\mathbf{1 4}$ (Fig. 4) within the hormone-binding pocket. Specifically, they showed that the orientation of 3-R-methylpyrrolidine 13a was responsible for the compound being a pure $\operatorname{ER} \alpha$ (estrogen receptor $\alpha$ ) antagonist and a selective ER degrader (PA-SERD) for the treatment of breast cancer, opposite to the 3-S-methylpyrrolidine 13b and the unsubstituted derivative 14. This is due to the capability of the $R$-methyl group of compound 13a to increase the mobility in the loop connecting helices 11 and 12 (H11-12 loop) of the ER $\alpha$ protein.

\subsection{Introduction of a Cis-3,4-Diphenylpyrrolidine Moiety Provides a Potent Inverse Agonist of RORyt}

Recently, Jiang et al. [40] demonstrated that replacing a non-stereochemical with a stereochemical group was beneficial for the activity of a new series of cis-3,4-diphenylpyrrolidine derivatives as inverse agonists of the retinoic acid-related orphan receptor $\gamma(\mathrm{ROR} \gamma \mathrm{t})$ - a splice variant of the nuclear hormone receptor subfamily ROR $\gamma$ involved in autoimmune diseases. The design of the new molecules started by studying the binding conformation of bicyclic sulfonamide 15 (Fig. 5), which showed excellent potency towards ROR $\gamma \mathrm{t}(12 \mathrm{nM})$ but suffered from undesirable activity against pregnane $\mathrm{X}$ receptor $\left(\mathrm{PXR}, \mathrm{EC}_{50}=144 \mathrm{nM}, Y_{\max }=100 \%\right.$ ), which upregulates proteins involved in the detoxification and clearance of foreign toxic substances from the body. In the X-ray co-crystal structure of compound $\mathbf{1 5}$ in $\mathrm{ROR} \gamma \mathrm{t}$, the sulfonyl group assumes a pseudo-axial orientation with respect to the

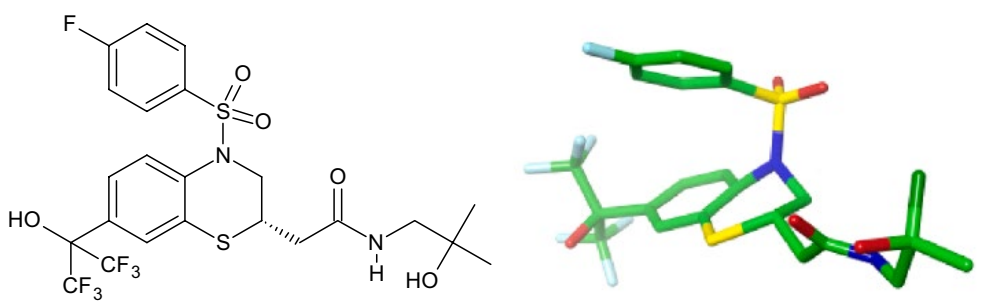

15

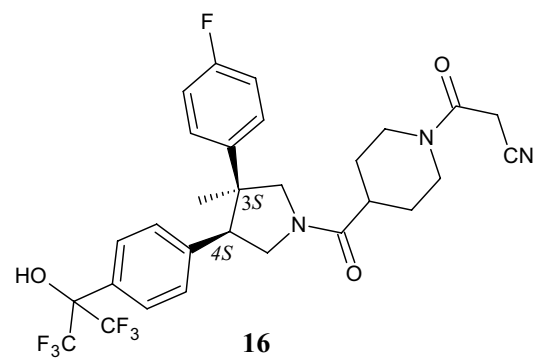

Fig. 5 Structures of retinoic acid-related orphan receptor $\gamma(\mathrm{ROR} \gamma \mathrm{t})$ ligands $\mathbf{1 5}$ and its ROR $\gamma \mathrm{t}$ binding conformation (top right) [40] as well as $\mathbf{1 6}$ 
benzothiazine moiety, while the folding of the para-F-phenyl ring creates face-toface $p i$ stacking interactions with the benzene ring of the benzothiazine moiety, as shown in the upper panel of Fig. 5. This "U-shaped" conformation was maintained by replacing the sulphonyl group with the cis-3,4-diphenylpyrrolidine scaffold. Lead optimization led to piperidinyl carboxamide 16 (Fig. 5), which proved a balance between potency against $\mathrm{ROR} \gamma \mathrm{t}$ with an $\mathrm{EC}_{50}$ of $61 \mathrm{nM}$ and a considerably lower PXR activity $\left(\mathrm{EC}_{50}=495, Y_{\max }=46 \%\right)$. Remarkably, (1) the cis-configuration accommodates the two phenyl rings close to the face-to-face stacked arrangement, (2) the hexafluoroisopropyl alcohol moiety establishes a hydrogen bonding interaction between the hydroxy group and His479 of ROR $\gamma$ t, (3) transposition of the C3 methyl group in $\mathrm{C} 4$ position leads to the loss of ROR $\gamma$ t potency. In addition, (4) pyrrolidines with an unsubstituted nitrogen were weak agonists compared with tertiary amines, and (5) a para-F substituent in the 3-phenyl ring improved $\mathrm{EC}_{50}$ values.

\subsection{Basicity and Nucleophilicity of the Pyrrolidine Nucleus}

While substituents at C-4 of proline affect the puckering of the ring, substituents at C-2 of pyrrolidine shift its basicity. In fact, the nitrogen atom of pyrrolidine, as a secondary amine, confers basicity to the scaffold. In this context, An et al. [41] investigated the basicity of a set of 28 pyrrolidines used as organocatalysts, showing that particularly charged substituents have a strong effect on the basicity. Lastly, due to its nucleophilicity, the pyrrolidine nitrogen represents a privileged position for substitutions, with $92 \%$ of all US FDA approved pyrrolidine drugs being substituted at the $N-1$ position [21].

\subsection{Spatial Characteristics Influencing the Biological Activities of Pyrrolidine Derivatives}

In summary, the advantages of using the pyrrolidine scaffold in drug design are due to the unrestricted conformation of the ring, which can be controlled and locked by the appropriate choice of substituents. Indeed, inductive and stereoelectronic factors influence the puckering of the pyrrolidine ring and, consequently, its pharmacological efficacy. The following list summarizes the spatial dispositions of the pyrrolidine scaffold that affect the biological activity towards specific targets cited in this chapter:

- cis-4- $\mathrm{CF}_{3}$ substituent on the pyrrolidine scaffold endorses the pseudo-axial conformation of the groups in the other positions, leading compounds able of showing full agonism in both the human and mice GRP40 receptor;

- compared with 3-S-methylpyrrolidine or an unsubstituted pyrrolidine, 3- $R$-methylpyrrolidine promotes a pure ER $\alpha$ antagonist and selective ER degrader (PASERD) for the treatment of breast cancer;

- the introduction of a chiral pyrrolidine into molecules promotes selectivity towards CK1 receptors. However, the selectivity and potency for the CK1 $1 \gamma$ 
isoform is due to the methylene group at position 2 being involved in spontaneous intramolecular Pictet-Splenger cyclization during crystallization with the protein;

- a cis-3,4-diphenylpyrrolidine scaffold gives the molecule a "U-shape" conformation that is beneficial for inverse agonistic activity on the ROR $\gamma t$ receptor.

\section{Pyrrolidine Derivatives Obtained by Ring Synthesis}

\subsection{Pyrrolidines Obtained by 1,3-Dipolar Cycloadditions}

A classical method for the preparation of five-membered heterocycles is the 1,3-dipolar cycloaddition [42] between a 1,3-dipole, such as a nitrone, an azide or an azomethine ylide, with a dipolarophile, typically an olefin, both of which are responsible for the regio- and stereoselectivity of the reaction [29, 43]. In particular, for synthetic pyrrolidines, the 1,3-dipolar cycloaddition reaction between nitrogenbased 1,3-dipole azomethine ylides with alkenyl dipolarophiles has been studied extensively. As shown in Fig. 6, stereoselectivity at positions 2 and $5\left(\mathrm{R}^{1}\right.$ and $\left.\mathrm{R}^{2}\right)$ depends on the shape of the ylides, whereas stereochemistry in positions 3 and 4 correlates with the relative orientation of the substituents of the dipolarophile, leading to 3,4-cis- or 3,4-trans-substituted pyrrolidines [44].

Exploiting the 1,3-dipolar cycloaddition process between $N$-(methoxymethyl)$N$-(trimethylsilylmethyl)benzylamine 17 and methyl acrylate 18 (Fig. 7) under acid conditions in the presence of trifluoroacetic acid (TFA), Min et al. [45] synthesized a series of benzimidazole carboxamides 19a-p bearing the pyrrolidine nucleus at position 2. In particular, they functionalized the pyrrolidine nitrogen by introducing different aromatic rings and tested the compounds as inhibitors of poly(ADP-ribose)

\section{Ylides:}<smiles>[R]C=[N+]([R])C[Y19]</smiles>

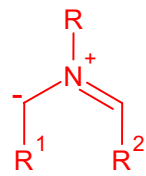

U shape<smiles>[R]C=[N+]([R])[CH]C</smiles><smiles>[R]C=[N+]([R])C[R]</smiles>

S shapes

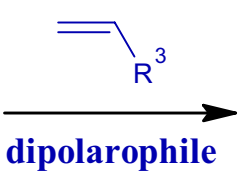

dipolarophile

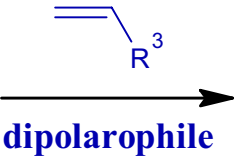

dipolarophile<smiles>[R]CC1CCC([R])N1[R]</smiles>

$2,5-$ cis<smiles>[R][C@@H]1C[C@@H]([R])N([R])[C@@H]1[R]</smiles>

2,5-trans

Fig. 6. 1,3-Dipolar cycloadditions to stereoselectively obtain pyrrolidine derivatives 


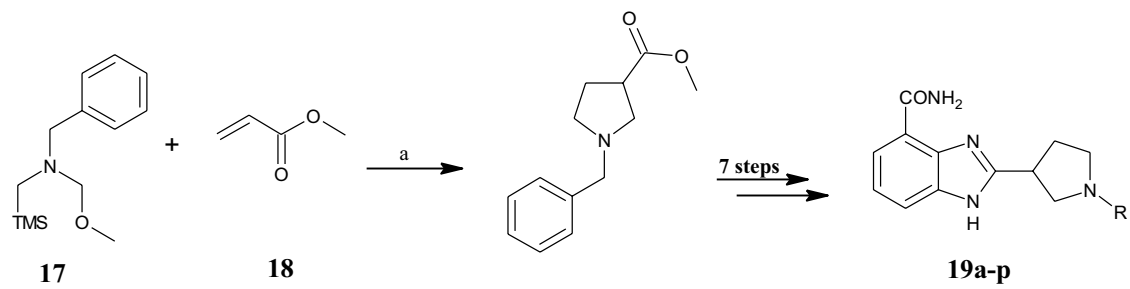

\begin{tabular}{|c|c|c|c|c|c|}
\hline Comp & $\mathbf{R}$ & $\begin{array}{c}\text { PARP-1 } \\
\text { inhibition \% }\end{array}$ & $\begin{array}{c}\text { PARP-2 } \\
\text { inhibition \% }\end{array}$ & $\begin{array}{c}\text { PARP-1 } \\
\text { IC }_{50}[\mathrm{nM}]\end{array}$ & $\begin{array}{c}\text { PARP-2 } \\
\text { IC }_{50}[\mathrm{nM}]\end{array}$ \\
\hline $19 a$ & $-\mathrm{CH}_{2}(\mathrm{CO}) \mathrm{NH}-$ phenyl & 17.6 & 34.5 & $T$ & $T$ \\
\hline $19 b$ & $-\left(\mathrm{CH}_{2}\right)_{2}(\mathrm{CO}) \mathrm{NH}$-phenyl & 19.9 & 41.2 & / & / \\
\hline $19 \mathrm{c}$ & $-\left(\mathrm{CH}_{2}\right)_{3}(\mathrm{CO})$-phenyl & 42.8 & 62.3 & 12.2 & 5.8 \\
\hline 19d & $-\mathrm{CH}_{2}(\mathrm{CO})$-phenyl & -1.1 & 7.2 & / & / \\
\hline 19e & $-\left(\mathrm{CH}_{2}\right)_{3}-N$-isatin & 22.0 & 74.5 & / & / \\
\hline $19 f$ & $-\mathrm{CH}_{2} \mathrm{CH}(\mathrm{OH})$-phenyl & 5.0 & 9.0 & / & / \\
\hline $19 \mathrm{~g}$ & $-\left(\mathrm{CH}_{2}\right)_{2} \mathrm{CH}(\mathrm{OH})$-phenyl & -2.1 & 6.5 & / & / \\
\hline $19 \mathrm{~h}$ & $-\left(\mathrm{CH}_{2}\right)_{3} \mathrm{NH}-$ phenyl & 47.5 & 66.2 & 7.1 & 3.3 \\
\hline $19 \mathbf{i}$ & $-\left(\mathrm{CH}_{2}\right)_{2}(\mathrm{CO})$-phenyl-4-OCH & 59.2 & 62.5 & 5.9 & 4.5 \\
\hline $19 j$ & $-\left(\mathrm{CH}_{2}\right)_{2}(\mathrm{CO})$-phenyl-4-Cl & 65.7 & 65.6 & 3.9 & 4.2 \\
\hline $19 k$ & $-\left(\mathrm{CH}_{2}\right)_{2}-N$-isatin & 6.0 & 37.1 & / & / \\
\hline 191 & $-\left(\mathrm{CH}_{2}\right)_{3}-\mathrm{NH}_{2}$ & 26.8 & 46.4 & / & / \\
\hline $19 \mathrm{~m}$ & $-\left(\mathrm{CH}_{2}\right)_{2}-\mathrm{NH}_{2}$ & 24.8 & 32.8 & / & / \\
\hline $19 n$ & $-\left(\mathrm{CH}_{2}\right)_{3}-\mathrm{NH}-(\mathrm{CO})$-phenyl & 19.4 & 39.1 & I & l \\
\hline 190 & $-\left(\mathrm{CH}_{2}\right)_{2}-\mathrm{NH}-(\mathrm{CO})$-phenyl & 38.4 & 66.2 & 11.1 & 5.7 \\
\hline $19 p$ & $-\left(\mathrm{CH}_{2}\right)_{2}(\mathrm{CO})$-phenyl & 68.0 & 76.7 & 3.6 & 3.2 \\
\hline Veliparib & l & 63.7 & 78.3 & 5.3 & 1.6 \\
\hline
\end{tabular}

Fig. 7 General synthetic scheme to benzimidazole carboxamides 19a-p. $\mathrm{R}$ substituents and poly(adenosine 5'-diphosphate (ADP)-ribose) polymerase (PARPs) inhibition assay of compounds 19ap. PARP-1 and -2 inhibition (\%) were evaluated at $10 \mathrm{nM}$. Reagents and conditions: $a$ trifluoroacetic acid (TFA), dichloromethane (DCM), 17 h, room temperature (r.t.), yield: $96 \%$

polymerase-1 and -2 (PARP-1,-2), enzymes involved in the DNA damage repair process, as depicted in Fig. 7.

Out of 16 compounds, 6 , namely 19c,h-j, $\mathbf{0 , p}$, inhibited PARP-1 and -2 with $\mathrm{IC}_{50}$ values $\leq 10 \mathrm{nM}$. Structure-activity relationship (SAR) analysis revealed that the length of the alkyl chain and the presence of the carbonyl group greatly influence biological activity. Overall, the most promising derivatives were the phenyl ketone derivatives $19 \mathbf{c}, \mathbf{i}, \mathbf{j}, \mathbf{p}$, rather than the $N$-phenylamine $19 \mathrm{~h}$ or the $N$-benzamide 190 derivatives. Comparing the activity within the entire class of phenyl ketone derivatives bearing 2-4 carbon atoms in the alkyl chain (19c,d,i,j,p), compounds $\mathbf{1 9 i}, \mathbf{j}, \mathbf{p}$ with the 3-carbon atom chain were the most active. Docking studies highlighted that the phenyl ketone fragments of compounds 19j and 19p would bind the three important amino acid residues Gly-863, Ser-904 and Glu-988 of PARP-1, instead of only 
Gly-863 and Ser-904 as in compounds 19c and 19d. Additionally, Van der Waals or hydrophobic interactions between the side chain of the compounds and the residues in the active site of PARP-1 were thought to facilitate the binding of these benzimidazole carboxamides. Electron donating or withdrawing groups in the para position of the benzene ring, as in compounds $\mathbf{1 9} \mathbf{i}$ and $\mathbf{1 9} \mathbf{j}$, caused inhibitory activity similar to the reference compound veliparib, but with slightly higher $\mathrm{IC}_{50}$ values compared with the unsubstituted derivative 19p. Reduction of the carbonyl group to a hydroxy group (19f and $19 \mathrm{~g}$ ), the presence of hydrophilic amine chains (19l and $19 \mathrm{~m})$, or the bulky phthalimide group (19e and 19k), were detrimental for enzymatic inhibition. Cytotoxic assays against MDA-MB-436 (breast cancer) and CAPAN-1 (pancreatic cancer) cell lines confirmed $\mathbf{1 9} \mathbf{j}$ as the most promising compound $\left(\mathrm{IC}_{50} 17.4\right.$ and $11.4 \mu \mathrm{M}$, respectively), followed by $\mathbf{1 9 p}\left(\mathrm{IC}_{50} 19.8\right.$ and $15.5 \mu \mathrm{M}$, respectively), which had $\mathrm{IC}_{50}$ values much lower than those of the reference compounds olaparib ( $\mathrm{IC}_{50} 30.2$ and $100 \mu \mathrm{M}$, respectively, in MDA-MB-436 and CAPAN-1 cells) and veliparib ( $\mathrm{IC}_{50} 100 \mu \mathrm{M}$ in both cell lines).

The same dipolar reagent $N$-(methoxymethyl)- $N$-(trimethylsilylmethyl)benzylamine $\mathbf{1 7}$ was reacted with the nitrovinyl substrate 20, methyl trans-4-fluorocinnamate 21, and chalcone 22, in the presence of a catalytic amount of TFA, by Wang et al. [46] to synthesize 3,4-disubstituted pyrrolidine sulfonamides 23a-y, 23z-ac, and 23ad, respectively (Fig. 8). All compounds were prepared as enantiomerically pure trans isomers and tested as selective glycine transporter-1 (GlyT1) competitive inhibitors. The major role of GlyT1 is to maintain glycine concentration below saturation level at the postsynaptic ionotropic glutaminergic $N$-methyl-D-aspartate (NMDA) receptor. Since the aetiology of schizophrenia has been linked to impaired glutamatergic neurotransmission involving the NMDA receptor, the development of GlyT1 inhibitors may represent a putative treatment for it and other disorders associated with NMDA receptor hypofunction. The new pyrrolidine sulfonamides 23a-ad were synthesized based on the SAR investigation conducted on the reference compound 23a. The latter displayed satisfactory GlyT1 inhibitory potency in vitro, with a $K_{\mathrm{i}}$ value of $0.198 \mu \mathrm{M}$, but a high efflux ratio (ER) of 8.7, indicating it as potential substrate of P-glycoprotein (P-gp) - the most relevant efflux transporter expressed in blood-brain barrier (BBB). The transformation of the sulfonamide moiety into amides, carbamides, tertiary amines, and urea groups, including the pyrrolidine nitrogen, produced inactive inhibitors of GlyT1 (structures not shown). The replacement of the benzoyl group of compound 23a by aryl substituents $\left(\mathrm{R}^{2}\right)$ gave excellent outcomes, providing new potent analogues such as $\mathbf{2 3 d}, \mathbf{f}-\mathbf{i}, \mathbf{k}, \mathbf{l}, \mathbf{0}-\mathbf{t}, \mathbf{y}, \mathbf{z}$ with single or double digit nanomolar activity. Among these, the anilines $\mathbf{2 3 d}, \mathbf{g}-\mathbf{i}, \mathbf{k}, \mathbf{l}, \mathbf{l}, \mathbf{p}, \mathbf{p}, \mathbf{v}, \mathbf{x}$ also exhibited lower ER values and consequently less susceptibility to P-gp efflux. Comparable in vitro potency and ER values were obtained when replacing the 1-methylimidazole moiety by a 1-methyl-1,2,3-triazole substituent obtaining compound 23u, which proved metabolically unstable. As reported in Fig. 8, the fluorophenyl substituents at position $3\left(\mathrm{R}^{1}\right)$ of the pyrrolidine sulfonamides offered better in vitro potency and ER profile, followed by the unsubstituted phenyl ring (23b-f). Concerning $\mathrm{R}^{2}$ substituents, meta-substituted derivatives showed improved biological activity. Instead, the activity of compounds with heteroaromatic substituents in position 4 $(\mathbf{2 3 j}, \mathbf{m}, \mathbf{q}, \mathbf{r})$ was influenced by the number and position of the nitrogen atoms of the 

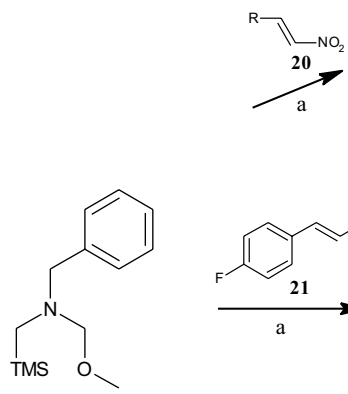

17
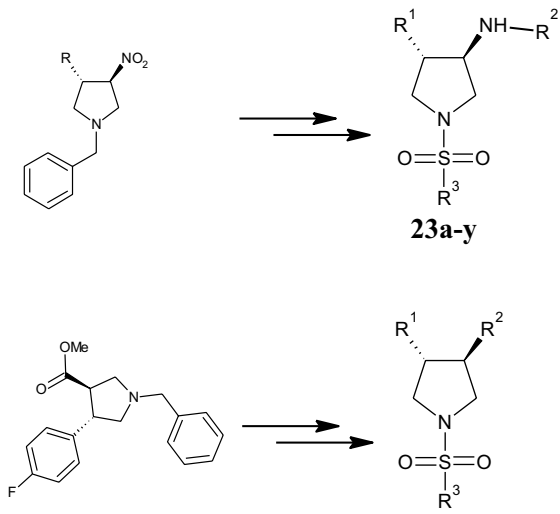

23z-ac

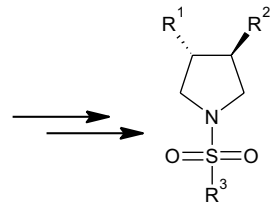

$23 \mathrm{ad}$

\begin{tabular}{|c|c|c|c|c|c|}
\hline Comp & $\mathbf{R}^{1}$ & $\overline{\mathbf{R}^{2}}$ & $\overline{\mathbf{R}^{3}}$ & ER & $\begin{array}{c}\mathbf{K}_{\mathbf{i}} \\
{[\mu \mathrm{M}]}\end{array}$ \\
\hline $23 a$ & phenyl & $\begin{array}{c}\text { 2-Cl,3-CF} \text { 3-phenyl- } \\
\text { methanone }\end{array}$ & 1- $\mathrm{CH}_{3}$ - $1 H$-imidazol-4-yl & 8.7 & 0.198 \\
\hline 23b & phenyl & phenyl & 1- $\mathrm{CH}_{3}-1 H$-imidazol-4-yl & 0.9 & 0.199 \\
\hline $23 c$ & phenyl & 2- $\mathrm{CH}_{3}$-phenyl & 1- $\mathrm{CH}_{3}-1 H$-imidazol-4-yl & 1.3 & 1.51 \\
\hline 23d & phenyl & 3- $\mathrm{CH}_{3}$-phenyl & 1- $\mathrm{CH}_{3}-1 H$-imidazol-4-yl & 0.9 & 0.018 \\
\hline 23e & phenyl & 4- $\mathrm{CH}_{3}$-phenyl & 1- $\mathrm{CH}_{3}-1 H$-imidazol-4-yl & 0.6 & 1.25 \\
\hline $23 \mathrm{f}$ & phenyl & 3-CF3-phenyl & 1- $\mathrm{CH}_{3}-1 H$-imidazol-4-yl & - & 0.008 \\
\hline $23 g$ & 4-F-phenyl & 3- $\mathrm{CF}_{3}$-phenyl & 1- $\mathrm{CH}_{3}-1 H$-imidazol-4-yl & 0.9 & 0.003 \\
\hline $23 \mathrm{~h}$ & 4-F-phenyl & 3-Cl-phenyl & 1- $\mathrm{CH}_{3}-1 H$-imidazol-4-yl & 1.1 & 0.003 \\
\hline $23 \mathbf{i}$ & 4-F-phenyl & 3-CF 3 ,4-F-phenyl & 1- $\mathrm{CH}_{3}-1 H$-imidazol-4-yl & 0.8 & 0.005 \\
\hline $\mathbf{2 3} \mathbf{j}$ & 4-F-phenyl & 5- $\mathrm{CF}_{3}$-pyridin-3-yl & 1- $\mathrm{CH}_{3}-1 H$-imidazol-4-yl & 10 & 1.16 \\
\hline
\end{tabular}

Fig. 8 General synthetic scheme to pyrrolidine sulfonamides $23 a-a d$. $E R$ Efflux ratio values. $K_{\mathrm{i}}$ values towards hGLYT1 [46]. Reagents and conditions: $a$ TFA (catalyst), DCM, r.t., overnight

heteroaromatic, as shown in Fig. 8. Finally, the analogue 23t $\left(\mathrm{R}^{2}=\right.$ indanyl) showed the best balance between potency and ER value $\left(K_{\mathrm{i}}=0.001 \mu \mathrm{M}, \mathrm{ER}=1.5\right)$.

1,3-Dipolar cycloadditions between $N$-(methoxymethyl)- $N$-(trimethylsilylmethyl) benzylamine 17 and cis- or trans-alkenyl ester derivatives 24 (Fig. 9) in TFA, were used by Zhang et al. [47] to gain a series of 4-benzylpyrrolidine-3-carboxylic acid derivatives as potent agonists at peroxisome proliferator-activated receptors (PPARs). Among the new pyrrolidines, the cis-3R,4S-configured compounds 25 and 26 (Fig. 9) combine agonistic activity at PPAR $\alpha$ and PPAR $\gamma$, restoring glucose 


\begin{tabular}{|c|c|c|c|c|c|}
\hline $23 k$ & 3-F-phenyl & 3-Cl-phenyl & 1- $\mathrm{CH}_{3}$ - $1 H$-imidazol-4-yl & 1 & 0.042 \\
\hline 231 & 2-F-phenyl & 3-Cl-phenyl & 1- $\mathrm{CH}_{3}-1 H$-imidazol-4-yl & 0.9 & 0.021 \\
\hline $23 \mathrm{~m}$ & 4-F-phenyl & 2-CF3-pyridin-4-yl & 1- $\mathrm{CH}_{3}-1 H$-imidazol-4-yl & 18.5 & 0.118 \\
\hline $23 n$ & pyridin-3yl & 3- $\mathrm{CF}_{3}$-phenyl & $1-\mathrm{CH}_{3}-1 H$-imidazol-4-yl & - & 0.766 \\
\hline 230 & 4-F-phenyl & 3-CF3-phenyl & 1- $\mathrm{CH}_{3}-1 H$-imidazol-4-yl & 0.8 & 0.002 \\
\hline $23 p$ & 4-F-phenyl & 3-OCF 3-phenyl & 1- $\mathrm{CH}_{3}$ - $1 H$-imidazol-4-yl & 0.7 & 0.004 \\
\hline $23 q$ & 4-F-phenyl & 4- $\mathrm{CF}_{3}$-pyridin-2-yl & 1- $\mathrm{CH}_{3}$ - $1 H$-imidazol-4-yl & 1.3 & 0.008 \\
\hline $23 \mathbf{r}$ & 4-F-phenyl & 6- $\mathrm{CF}_{3}$-pyrimidin-4-yl & 1- $\mathrm{CH}_{3}-1 H$-imidazol-4-yl & 7.5 & 0.005 \\
\hline 23s & 4-F-phenyl & 3-OCF 3 ,4-F-phenyl & 1- $\mathrm{CH}_{3}-1 H$-imidazol-4-yl & 0.7 & 0.002 \\
\hline $23 t$ & 4-F-phenyl & 2,3-dihydro-1 $H$-inden-1-yl & 1- $\mathrm{CH}_{3}$ - $1 H$-imidazol-4-yl & 1.5 & 0.001 \\
\hline $23 u$ & 4-F-phenyl & 3- $\mathrm{CF}_{3}, 4-\mathrm{F}-$ phenyl & 1- $\mathrm{CH}_{3}-1 H-1,2,3$-triazole-4-yl & 0.5 & 0.003 \\
\hline $23 v$ & $\begin{array}{c}(R)- \\
\text { esahydro-2 } H \text {-pyran-2-yl }\end{array}$ & 3- $\mathrm{OCF}_{3}$-phenyl & 1- $\mathrm{CH}_{3}-1 H$-imidazol-4-yl & 0.8 & 0.003 \\
\hline $23 w$ & $(S)$-tetrahydro- $2 H$-furan-2yl & 3-OCF 3-phenyl & 1- $\mathrm{CH}_{3}$ - $1 H$-imidazol-4-yl & - & 0.024 \\
\hline $23 x$ & 1,3-dioxepan-2-yl & 3-OCF 3 -phenyl & $1-\mathrm{CH}_{3}-1 H$-imidazol-4-yl & 0.9 & 0.002 \\
\hline $23 y$ & 1,3-dioxan-2-y & 3-OCF 3-phenyl & 1- $\mathrm{CH}_{3}-1 H$-imidazol-4-yl & 1.1 & 0.002 \\
\hline $23 z$ & 4-F-phenyl & 3-OCF 3 -phenoxymethyl & 1- $\mathrm{CH}_{3}$ - $1 H$-imidazol-4-yl & - & 0.007 \\
\hline 23aa & 4-F-phenyl & 3-OCF 3 -phenylmethanone & 1- $\mathrm{CH}_{3}$ - $1 H$-imidazol-4-yl & 1.3 & 0.029 \\
\hline 23ab & 4-F-phenyl & $\begin{array}{c}3-\mathrm{OCF}_{3}- \\
\text { phenylaminomethyl }\end{array}$ & 1- $\mathrm{CH}_{3}-1 H$-imidazol-4-yl & 1.2 & 0.060 \\
\hline 23 ac & 4-F-phenyl & $\begin{array}{l}\text { 3-OCF } 3 \text {-phenyl- } \\
\text { aminomethanone }\end{array}$ & 1- $\mathrm{CH}_{3}$ - $1 H$-imidazol-4-yl & 7.2 & 0.36 \\
\hline 23ad & phenyl & benzyl & 1- $\mathrm{CH}_{3}-1 H$-imidazol-4-yl & 1.3 & 0.093 \\
\hline
\end{tabular}

Fig. 8 (continued)

metabolism and ameliorating dyslipidaemia associated with type 2 diabetes. Compounds 25 and 26 displayed $\alpha \mathrm{EC}_{50}$ and $\gamma \mathrm{EC}_{50}$ values in the low nanomolar range (5-90 nM). In addition, compound 26 was efficient in lowering fasting glucose and triglyceride levels in diabetic db/db mice after oral administration of a $10 \mathrm{mg} / \mathrm{kg}$ dose once daily. SAR studies revealed that (1) the oxybenzyl pyrrolidine acid series offered the best balance of PPAR $\alpha / \gamma$ functional activities, (2) the cis-configuration of the substituents in positions 3 and 4 of the pyrrolidine ring was preferred over the trans orientation, and (3) N-carbamoyl and N-aryl-substituted oxybenzyl pyrrolidine acid analogs provided potent balanced PPAR $\alpha / \gamma$ dual agonists.

Conjugated systems with biological macromolecules, including carbohydrates, lipids, proteins, and nucleic acids, require that special attention is paid to the geometry of the molecules to be combined. Unlike the pyrrolidine scaffold, spiro-pyrrolidine molecules have rigid conformations that allow for easy incorporation into biological macromolecules, including cholesterol. For this purpose, Periyasami et al. [48] synthesized a small set of novel spiro-pyrrolidine/pyrrolizines by one-pot three-component reactions. Stereo- and regioselective reactions based on 1,3-dipolar cycloaddition between the dipolarophile C3- $\beta$-cholesterolacrylate 27 (Fig. 9) under reflux in $i \mathrm{PrOH}$ for $2 \mathrm{~h}$ with azomethidine ylides, in turn generated in situ by reaction isatin, acenaphthoquinone, or ninhydrine with the secondary amino acids sarcosine or proline, allowed the desired compounds to be obtained as single isomers. All compounds were evaluated for their in vitro antibacterial activity 
<smiles>COCN(COC)Cc1ccccc1</smiles>

17<smiles>[X]/C=C\Cc1ccccc1</smiles>

24a,b

24a: $\mathrm{X}=\mathrm{CO}-\mathrm{Xc}(\mathrm{D})(\mathrm{Xc}-(\mathrm{D}))=$ D-camphorsultam 24b: $X=-C O O E t$<smiles>[X]C1CN(Cc2ccccc2)CC1Cc1ccccc1</smiles><smiles>[Y][Y](=C)C=CC</smiles>

25,26<smiles>C=CC(=O)OC1CC[C@]2(C)C(=CCC3C4CCC([C@H](C)CCCC(C)C)C4(C)CCC32)C1</smiles><smiles></smiles>

29
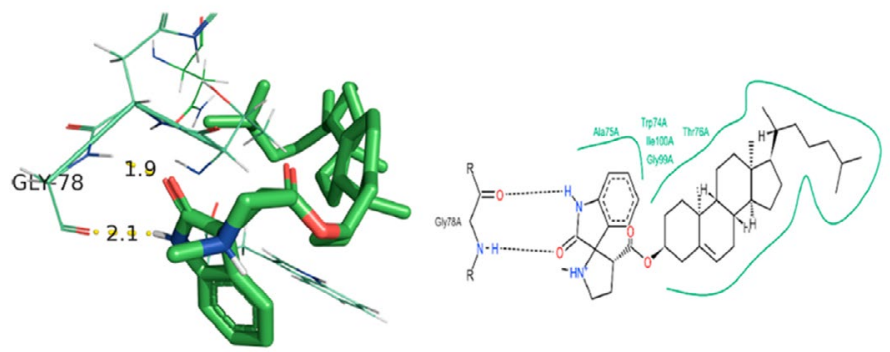

28

Fig. 9. 1,3-Dipolar cycloadditions to yield 4-benzylpyrrolidine-3-carboxylic acids 25 and 26, synthesis of cholesterol-conjugated spiro-pyrrolidine/pyrrolizines 28-30, and 3D/2D interaction diagrams of compound 28 with the active site of target receptor protein 1XFF [48]. Reagents and conditions: $a$ TFA (1 M solution in DCM); b isopropyl alcohol (iPrOH), 2 h, under reflux, yields: 76\% (28), 67\% (29), 63\% (30) 
against a panel of four human pathogens, including Vibrio cholerae, Proteus mirabilis, Micrococcus luteus, and Bacillus subtilis. The most active were compounds 28, 29, and 30 (Fig. 9), which showed good antimicrobial activity, causing zones of growth inhibition in the performed disc diffusion assays ranging from 13.0 to $15.1 \mathrm{~mm}$, at $50 \mu \mathrm{g} / \mathrm{ml}$. With the aim of investigating their biological potential as glucosamine-6-phospate synthase (Glc-N-6P) inhibitors, the authors performed in silico molecular docking studies with compounds 28-30 in the enzyme's active site (PDB ID: 1XFF). The results showed significant interactions with active site amino acids, revealing that the spiropyrrolidine moiety of compound $\mathbf{2 8}$ is engaged in two $\mathrm{H}$-bond interactions involving its $-\mathrm{NH}$ and $-\mathrm{CO}$ groups with those of the aliphatic nonpolar amino acid Gly78 (Fig. 9), thus demonstrating its prominent role in the inhibition of Glc-N-6-P synthase and thus in the antibacterial activity of the compounds.

By a one-pot multicomponent approach, Shyamsivappan et al. [49] synthesized phenyl/thiophene dispiro indenoquinoxaline pyrrolidine quinolone analogues, 36a-f and 37a-f (Fig. 10), via 1,3-dipolar cycloaddition reaction of (E)-3arylidine-8-nitro2,3-dihydroquinolin-4(1H)-ones 33a-f, ninhydrin 31, $o$-phenylenediamine 32 and benzylamine 34/thiophene methylamine 35 in $\mathrm{MeOH}$ under reflux for 2-3 h. All compounds were screened for anticancer activity against MCF-7 and HeLa cells, and only compound 37e showed good biological activity, with $\mathrm{IC}_{50}$ values of 17 and<smiles>O=C1c2ccccc2C(=O)C1(O)O</smiles>

31<smiles>Nc1ccccc1N</smiles>

32

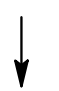

L<smiles>[R]c1ccc(/C=C2\CNc3c(cccc3[N+](=O)[O-])C2=O)cc1</smiles>

$\mathrm{R}=\mathrm{H}, \mathrm{Br}, \mathrm{Cl}, \mathrm{F}, \mathrm{CH}_{3}, \mathrm{OCH}_{3}$

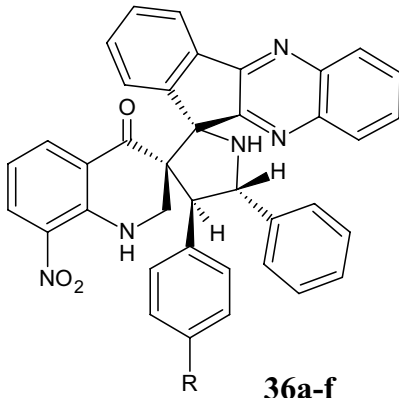

36a-f

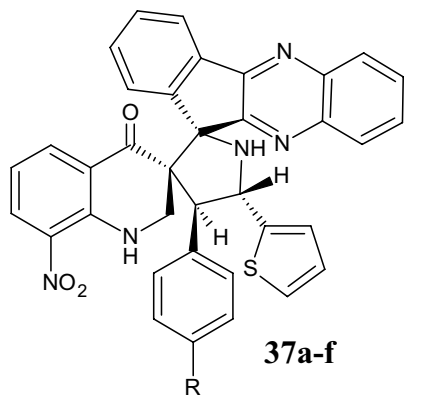

Fig. 10. 1,3-Dipolar cycloadditions to yield phenyl/thiophene dispiro indenoquinoxaline pyrrolidine quinolone derivatives 36a-f and 37a-f. Reagents and conditions: $a \mathrm{MeOH}$, under reflux, $2-3 \mathrm{~h}$, yields: $92-98 \%(36 \mathbf{a}-\mathbf{f})$ and $93-96 \%(37 \mathbf{a}-\mathbf{f})$ 
$19 \mu \mathrm{M}$, respectively, comparable to those of the reference compound doxorubicin (16 and $18 \mu \mathrm{M}$ against MCF-7 and HeLa cells, respectively). Overall, the thiophencontaining derivatives $37 \mathbf{a}-\mathbf{f}$ showed better activity against both cell lines $\left(\mathrm{IC}_{50}\right.$ in the range of 17 and $28 \mu \mathrm{M}$ against MCF-7, and 19 and $30 \mu \mathrm{M}$ against HeLa) than their respective counterparts bearing the phenyl ring 36a-f $\left(\mathrm{IC}_{50}\right.$ in the range of 22 and $29 \mu \mathrm{M}$ against MCF-7; and 26 and $37 \mu \mathrm{M}$ against HeLa). SAR analysis indicated that compounds 36e,f, and 37e,f, characterized by electron donating groups, such as methoxy and methyl had lower $\mathrm{IC}_{50}$ values than other derivatives with electron-withdrawing groups (EWGs). Further investigation into the mechanism behind the anticancer activity revealed that compound 37e induced apoptosis through intracellular reactive oxygen species (ROS)-mediated caspase-3 activation.

\subsection{Pyrrolidines Obtained by Pictet-Spengler-Oxidative Ring Contractions}

Moreover, spirocyclic motifs are emerging as an interesting feature for building block with low-molecular weight in the drug discovery field [50]. In 2016, Hati et al. [51] designed and synthesized a library of spiro[pyrrolidine-3,3'-oxindoles] 38a-n (Fig. 11) as potential anti breast cancer agents with a dual activity against histone deacetylase 2 (HDAC2) and prohibitin 2 (PHB2) enzymes. HDAC2 is responsible for the deacetylation of lysine residues on the N-terminal part of core histones $(\mathrm{H} 2 \mathrm{~A}$, $\mathrm{H} 2 \mathrm{~B}, \mathrm{H} 3$ and $\mathrm{H} 4$ ) and provides a tag for epigenetic repression, thus playing a significant role in transcriptional regulation, cell cycle progression, and developmental events. PHB2 acts as a mediator of transcriptional repression by nuclear hormone receptors via recruitment of histone deacetylases and works like an ER-selective coregulator, potentiating the inhibitory activities of anti-estrogens and repressing the activity of estrogens. Based on the DOS strategy, the new compounds 38a-n were synthesized via a one-pot Pictet Spengler-oxidative ring contraction of tryptamine, in the presence of water as reactant, mediated by stoichiometric N-bromosuccinimide (NBS) as oxidant, and a catalytic amount of TFA, varying the aromatic functionality of the pyrrole domain. Among all compounds produced, 38d,h,i inhibited the
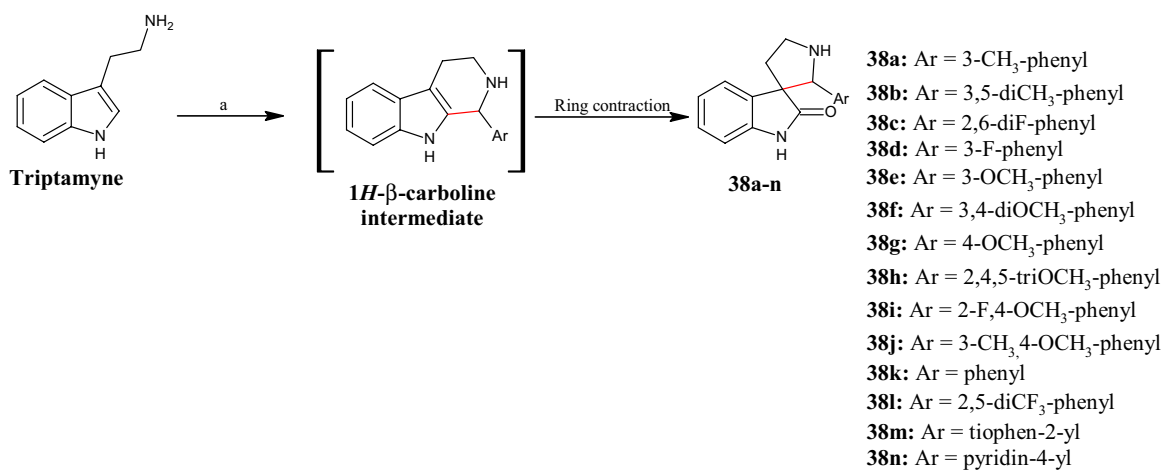

38a: $\mathrm{Ar}=3-\mathrm{CH}_{3}$-phenyl 38b: $\mathrm{Ar}=3,5-\mathrm{diCH}_{3}$-phenyl 38c: $\mathrm{Ar}=2,6-\mathrm{diF}-$ phenyl 38d: $\mathrm{Ar}=3-\mathrm{F}-$ phenyl 38e: $\mathrm{Ar}=3-\mathrm{OCH}_{3}-$ phenyl 38f: $\mathrm{Ar}=3,4-\mathrm{diOCH}_{3}$-phenyl 38g: $\mathrm{Ar}=4-\mathrm{OCH}_{3}-$ phenyl 38h: $\mathrm{Ar}=2,4,5$-triOCH${ }_{3}$-phenyl 38i: $\mathrm{Ar}=2-\mathrm{F}, 4-\mathrm{OCH}_{3}$-phenyl 38j: $\mathrm{Ar}=3-\mathrm{CH}_{3} 4-\mathrm{OCH}_{3}$-phenyl 38k: $\mathrm{Ar}=$ phenyl 381: $\mathrm{Ar}=2,5-\mathrm{diCF}_{3}$-phenyl 38m: $\mathrm{Ar}=$ tiophen-2-yl 38n: Ar $=$ pyridin-4-yl

Fig. 11 General synthetic scheme to spiro[pyrrolidine-3,3'-oxindoles] 38a-n. Reagents and conditions: $a$ ArCHO, NBS, water/tetrahydrofuran (THF), TFA (cat), $0{ }^{\circ} \mathrm{C}$ to r.t., yields: $45-94 \%$ 
growth of human breast cancer cell line MCF-7 by inducing apoptotic cell death at low micromolar $\mathrm{EC}_{50}$ values $(6.00,4.01$, and $3.53 \mu \mathrm{M}$, respectively). Chemical proteomics indicated HDAC2 and PHB2 as potential targets of the spiro[pyrrolidine3,3-oxindoles] and molecular docking of the most active compound 38i with HDAC2 (PDB ID: 4LY1) confirmed probable binding interactions. Overall, based on their cytotoxic effects, compounds characterized by electron-donating or weak EWGs on the phenyl ring showed higher MCF-7 cell growth inhibition rates compared with compounds bearing one or two strong EWGs.

\subsection{Pyrrolidines Obtained via Aminocyclizations}

Polyhydroxylated pyrrolidines, known as aza-sugars, are considered metabolically inert carbohydrates as they mimic the oxa-carbenium transition state from carbohydrate processing enzymes. Due to their central role in different biological activities, they are emerging as attractive compounds for the treatment of cancer and metabolic diseases. In 2019, using the double reductive amination reaction, Guazzelli et al. [52] developed a series of polyhydroxylated pyrrolidines, belonging to

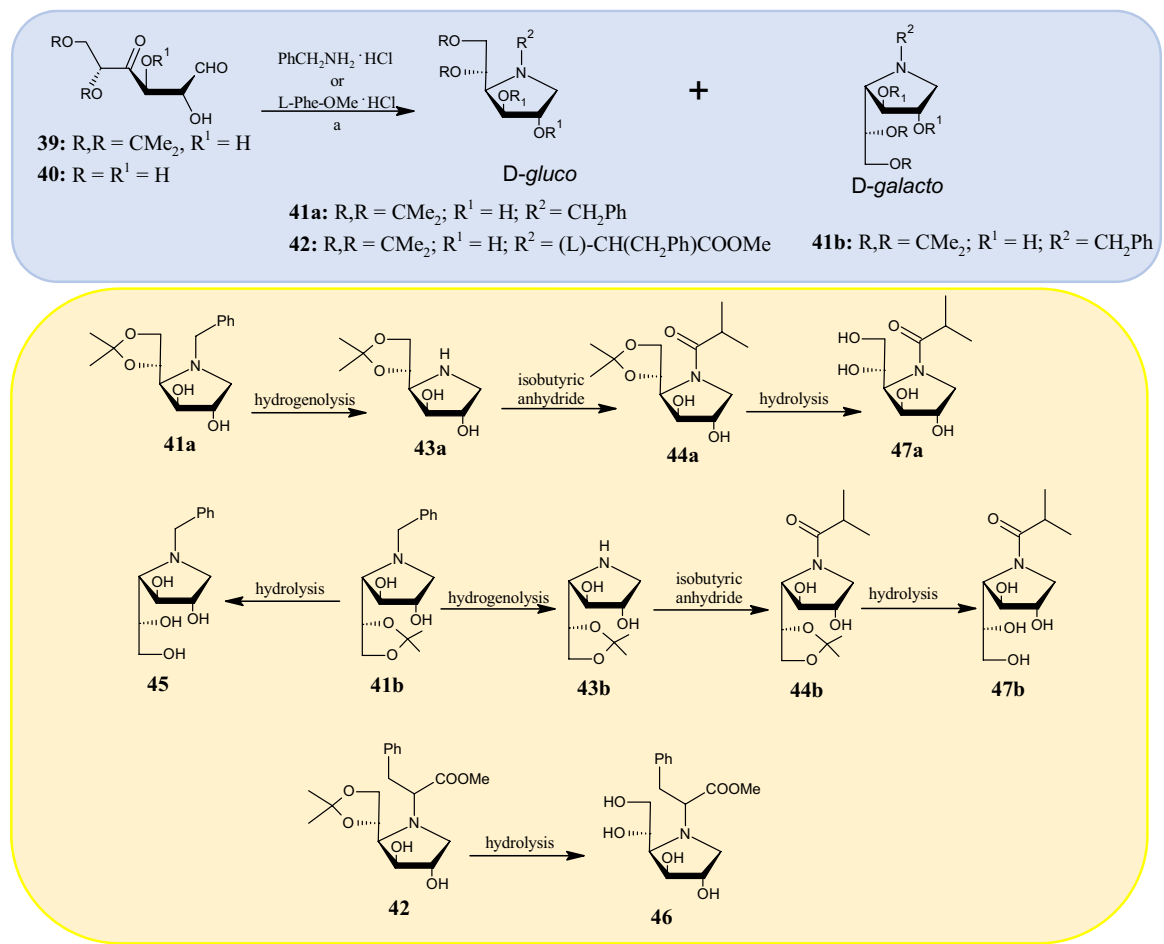

Fig. 12 Blue panel Synthesis of diastereoisomers $\mathbf{4 1 a , b}$ and $\mathbf{4 2}$ obtained by reaction of 5,6- $O$-isopropylidene-D-xylo-hexos-4-ulose 39 with benzylamine hydrochloride and L-phenylalanine methyl ester hydrochloride, respectively. Yellow panel Synthesis of final compounds 43a,b, 44a,b, 45, 46 and 47a,b. Reagents and conditions: $a$ sodium cyanoborohydride $\left(\mathrm{NaBH}_{3} \mathrm{CN}\right)$, methanol $(\mathrm{MeOH}) ; 60{ }^{\circ} \mathrm{C}, 24-48 \mathrm{~h}$, yields: $37 \%$ (41a,b), $44 \%$ (42) 
the diastereoisomeric D-glucose and D-galactose series, as dual-target inhibitors of the enzymes $\alpha$-glucosidase (AG) and aldose reductase (ALR2). Although AG represents the most important enzyme for controlling plasma sugar concentration, pathological changes in nervous, renal, vascular, and ocular systems of diabetic patients are caused by activation of ALR2. Therefore, ideal antidiabetic agents should be able to simultaneously block the catalytic activity of AG and ALR2. Aminocyclization was conducted by reacting aldohexos-4-ulose derivatives 39 and $\mathbf{4 0}$ (Fig. 12) with amines, including benzylamine, benzhydrylamine, ammonia, L- or D-phenylalanine methyl ester, and sodium cyanoborohydride $\left(\mathrm{NaBH}_{3} \mathrm{CN}\right)$ as reducing agent, to obtain mixtures of D-glucose and D-galactose diastereoisomers. Among these, the authors isolated as pure compounds only diastereoisomers 41a,b and 42 (Fig. 12) obtained by reaction of 5,6-O-isopropylidene-D-xylo-hexos-4-ulose 39 with benzylamine hydrochloride (for compounds 41a,b) and L-phenylalanine methyl ester hydrochloride (for compound 42). These three compounds were the starting material for the synthesis of other derivatives. Thus, through hydrogenolysis, compounds 43a,b were obtained and were, in turn, reacted with isobutyric anhydride to give compounds 44a,b. Finally, compounds $41 \mathbf{b}, \mathbf{4 2}$, and 44a,b were subjected to hydrolysis to remove the 5,6-O-isopropylidene protecting group affording compounds 45, 46, 47a,b, respectively, with enhanced hydrophilic character compared with the parent compounds. Among all, the D-galacto derivative $43 \mathbf{b}$ was able to reduce cell death and restore the physiological levels of oxidative stress, showing a percentage of enzyme inhibition at $100 \mu \mathrm{M}$ of $57.1 \%$ and $30.2 \%$ against ALR2 and AG, respectively.

Recently, Li et al. [53] reported a series of (S)-pyrrolidines as CXCR4 chemokine receptor antagonists with antimetastatic activity. The synthesis of compounds 51a-f (Fig. 13) was carried out in a multi-step manner in which intermediate pyrrolidine derivatives $\mathbf{5 0}$ were obtained by reaction of pyridin-2-yl-4-oxobutanal derivatives 48 with $(R)$-1-(4-methoxyphenyl)ethan-1-amine 49. Among all compounds generated, 51a with $\mathrm{R}^{1}=3-\mathrm{CH}_{3}$ showed excellent binding affinity to the $\mathrm{CXCR} 4$ receptor

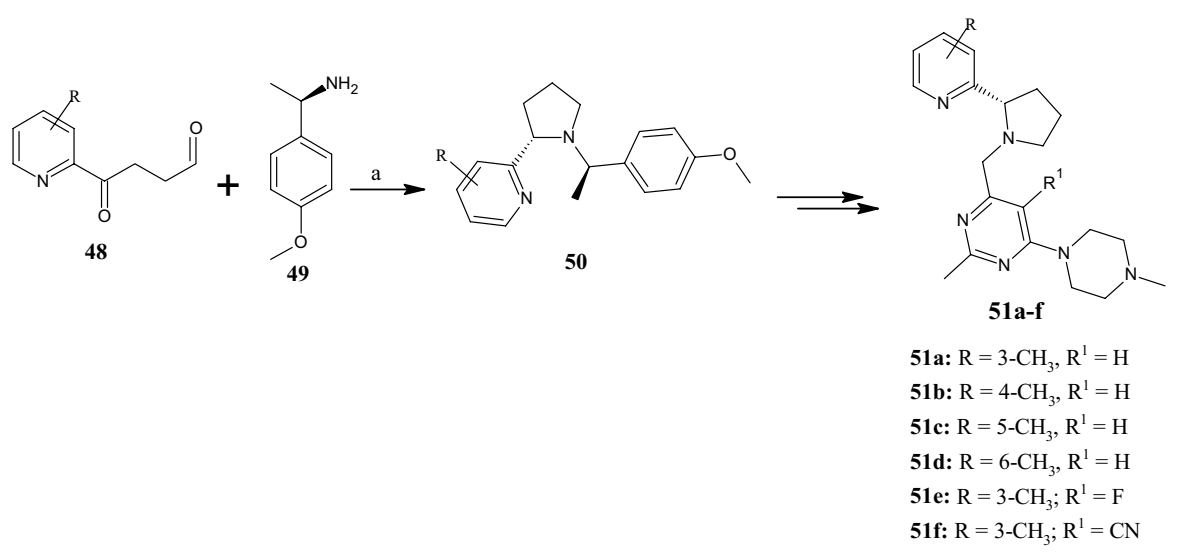

Fig. 13 General synthetic scheme to pyrrolidines 51a-f. Reagents and conditions: $a$ sodium triacetoxyborohydride $\left[\mathrm{NaBH}(\mathrm{OAc})_{3}\right], \mathrm{DCM},-70{ }^{\circ} \mathrm{C}$ to r.t., overnight, yields: $21-45 \%$ 
$\left(\mathrm{IC}_{50}=79 \mathrm{nM}\right.$ competitively displacing fluorescent 12G5 antibody). Conversely, by shifting the methyl group to other positions in the pyridine ring, the $\mathrm{IC}_{50}$ value increased to 216, 278 and $2391 \mathrm{nM}$ for compounds 51b, 51c and 51d, respectively. Another feature of compound 51a was its ability to inhibit CXCL12-induced cytosolic calcium flux $\left(\mathrm{IC}_{50}=0.25 \mathrm{nM}\right)$. In order to mitigate the overall basicity of the compounds, which can lead to issues such as hERG potassium channel inhibition, as well as CYP enzyme inhibition and phospholipidosis, the authors introduced a fluorine atom (compound 51e) or a cyano group (compound 51f) at the $\mathrm{R}^{1}$ position. However, this change greatly reduced the potency of compounds 51e and 51f, by 4- and 7-fold, respectively. Interestingly, the antimetastatic behavior of compound 51a was also shown in an in vivo tumor metastasis test conducted in mice, which received compound $\mathbf{5 1 a}$ intraperitoneally at a dose of $30 \mathrm{mg} / \mathrm{kg}$.

\subsection{Pyrrolidine-2-Ones Obtained by Cyclizations}

The interest in polyhydroxylated pyrrolidines led Da Silva et al. [54] to search for a short and alternative strategy to synthesize 1,4-dideoxy-1,4-imino-L-arabinitol

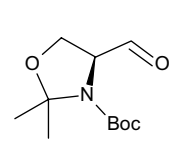

Garner's aldehyde 52

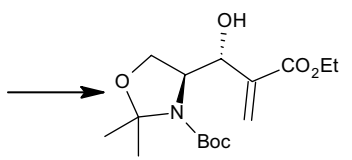

MBH adduct 53

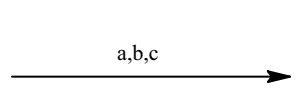<smiles>O=C1N[C@H](CO)[C@H](O)[C@H]1O</smiles>

d,e,f<smiles>OC[C@H]1NC[C@@H](O)[C@@H]1O</smiles>

Natural product 55<smiles>OC[C@H]1NC[C@@H](O)[C@@H]1O</smiles>

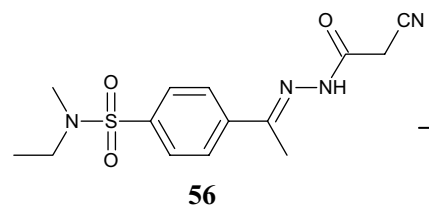

$\underset{\mathrm{g}}{\stackrel{\mathrm{ClCH}_{2} \mathrm{CN}}{\longrightarrow}}$

56

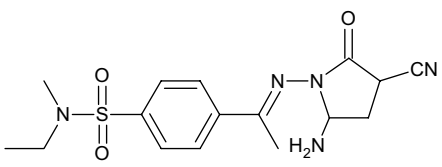

57

Fig. 14 General synthetic schemes to polyhydroxylated pyrrolidines $\mathbf{5 4}$ and pyrrolidone $\mathbf{5 7}$. Reagents and conditions: $a$ (1) $\mathrm{O}_{3}, \mathrm{MeOH},-78{ }^{\circ} \mathrm{C}, 40 \mathrm{~min}$; (2) DMS, $40 \mathrm{~min},-78{ }^{\circ} \mathrm{C}$ to r.t., not isolated; $b$ $\left[\mathrm{Zn}\left(\mathrm{BH}_{4}\right)_{2}\right], \mathrm{MeOH}$ or DCM, $-20^{\circ} \mathrm{C}, 2 \mathrm{~h}$, yield: $74 \% ; c$ TFA (2 equiv), DCM, $1 \mathrm{~h}$, yield: $74 \% ; d$ TBSCl, imidazole, DMF, 20 h, r.t., yield: $74 \% ; e \mathrm{BH}_{3}$. DMS, THF, 4 h, r.t., yield: $60 \%$; $f$ tetra- $n$-butylammonium fluoride (TBAF), THF, 12 h, r.t., yield: 99\%. g triethylamine (TEA), 1,4-dioxane, 5 h, under reflux, yield: $77 \%$ 
54 (Fig. 14). Compound 54 is a polyhydroxylated pyrrolidine that is a more potent $\alpha$-glycosidase (AG) inhibitor than its natural enantiomer compound 55 (Fig. 14). For this reason, compound $\mathbf{5 4}$ is reputed to be a potential starting point for new antidiabetic and anticancer drugs. As shown in Fig. 14, the synthetic route proposed for the synthesis of $\mathbf{5 4}$ comprises six steps starting from a chiral Morita-Baylis-Hillman $(\mathrm{MBH})$ adduct 53, which in turn was prepared from Garner's aldehyde 52. Compound $\mathbf{5 4}$ was obtained from an intermediate pyrrolidone, which was synthesized by a linear three-step reaction sequence involving ozonolysis of the double bond of the $\mathrm{MBH}$ adduct 53, followed by a stereoselective ketone reduction using zinc borohydride $\left[\mathrm{Zn}\left(\mathrm{BH}_{4}\right)_{2}\right]$, concomitant $N$-double deprotection/O-deprotection with TFA, and a final amidation reaction (cyclization). Finally, the pyrrolidone intermediate was (1) silylated to decrease water solubility, (2) reduced with borane-dimethyl sulfide, and finally, (3) O-deprotected with tetra- $n$-butylammonium fluoride (TBAF) to afford compound $\mathbf{5 4 .}$

By intermolecular cyclization reactions between 2-cyanoacetamide derivative 56 and chloroacetonitrile, in the presence of triethylamine (TEA), under reflux in 1,4-dioxane for $5 \mathrm{~h}$, Debbabi et al. [55] synthesized a series of $\mathrm{N}$-ethyl- $\mathrm{N}$-methyl benzenesulfonamides. Among these, derivative 57 (Fig. 14), characterized by a 5-amino-3-cyano-2-oxopyrrolidine core, showed antiproliferative activity against MCF-7 cells in the micromolar range $\left(\mathrm{IC}_{50}=62.53 \mu \mathrm{M}\right)$ and absence of cytotoxicity against normal fibroblasts of baby hamster kidney cell line (BHK). By docking studies, the activity of the compound was attributed to its binding to the dihydrofolate reductase (DHFR) (PDB ID: 4DFR).

\subsection{Pyrrolidine-2,5-Diones Obtained by Cyclizations}

Despite many years of research, it is still not clear how anticonvulsant drugs counteract seizures, but it is known that many of them interact with voltage-gated sodium channels (VGSCs) and voltage-gated calcium channels (VDCCs) in the central nervous system (CNS). In agreement with previous studies in which pyrrolidine2,5-dione emerged as valuable scaffold in the treatment of epilepsy [56], in 2017, Rybka et al. [57] synthesized a library of 1,3-disubstituted pyrrolidine-2,5-diones 59a-p (Fig. 15), obtained via cyclocondensations of dicarboxylic acids 58 with the properly substituted 1-(2-aminoethyl)- and 1-(3-aminopropyl)-4-arylpiperazines, at $180{ }^{\circ} \mathrm{C}$ for $1.5 \mathrm{~h}$. Derivatives 59a-p were administered intraperitoneally to mice and screened for their anticonvulsant activity by maximal electroshock (MES) and subcutaneous pentylenetetrazole (scPTZ) seizure tests in mice. Compounds 59j,n showed good activity in both tests $\left(\right.$ MES ED $50.88 .2 \mathrm{mg} \mathrm{kg}^{-1}$ and $101.5 \mathrm{mg} \mathrm{kg}^{-1}$, respectively; scPTZ $\mathrm{ED}_{50}: 65.7 \mathrm{mg} \mathrm{kg}^{-1}$ and $59.7 \mathrm{mg} \mathrm{kg}^{-1}$, respectively), indicating that they are able to prevent various kinds of seizures by blocking the sodium channel with higher affinity than phenytoin. SAR analysis revealed that the anticonvulsant activity is affected strongly by substituents at position 3 of the pyrrolidine2,5-dione scaffold. By scPTZ test, 3-benzhydryl 59a-d and 3-isopropyl 59e-h derivatives showed the most favorable protection in the scPTZ test, whilst 3-methyl 59i-l and unsubstituted 59m-p derivatives were more active in the MES test. Derivatives 

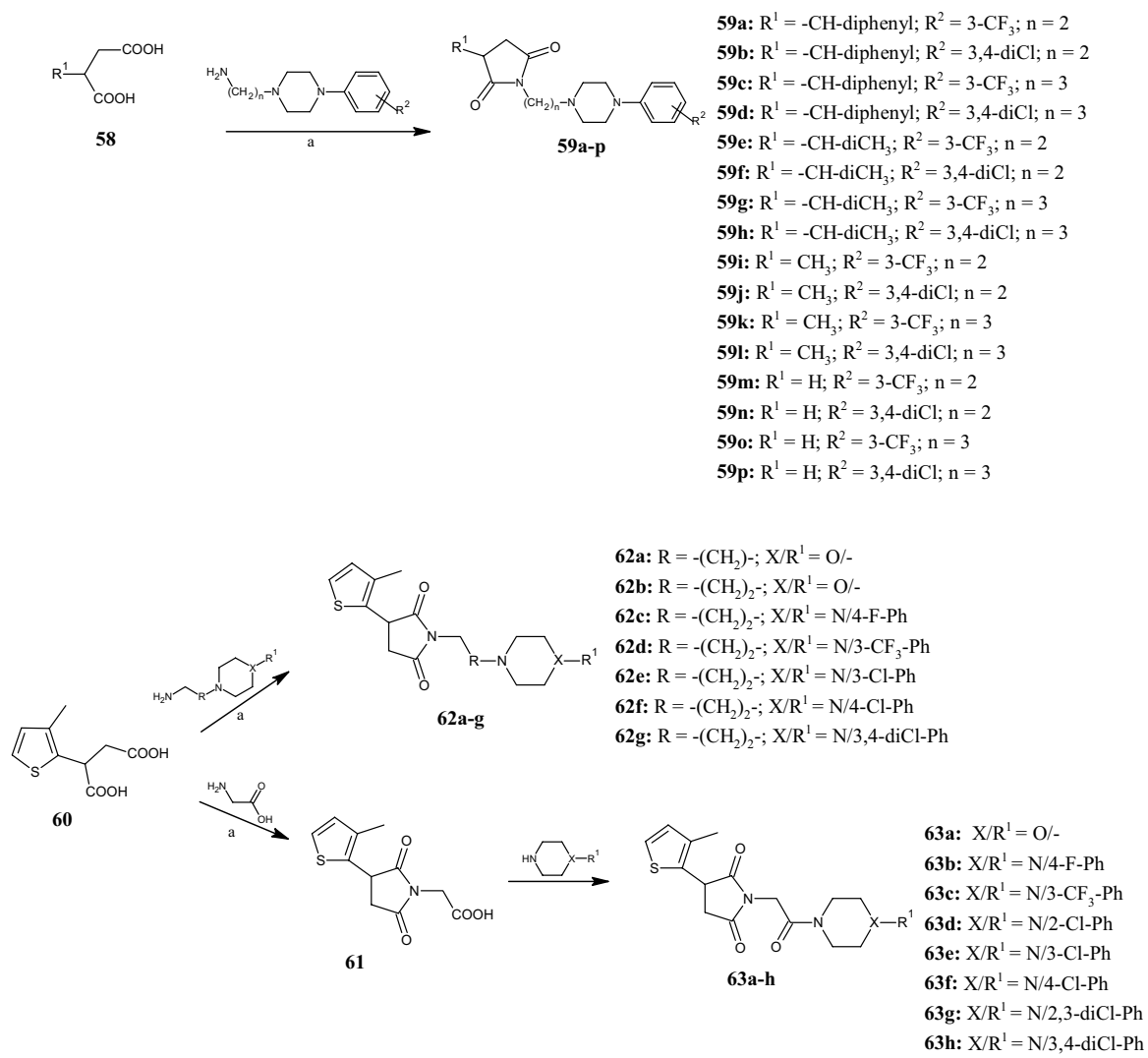

Fig. 15 General synthetic routes to pyrrolidine-2,5-diones 59a-p, 62a-g, and 63a-h. Reagents and conditions: $a 180{ }^{\circ} \mathrm{C}, 1.5$ h., yields: 60-82\% (59a-p), $70 \%(61), 54-86$ (62a-g)

with a phenylpiperazine moiety bearing a 3-trifluoromethyl group were most active in the MES test, whilst 3,4-dichlorophenylpiperazines were active in both the MES and scPTZ tests. Finally, the increase in length of the alkyl chain resulted in derivatives that displayed quick onset and long-lasting anticonvulsant activity. A similar class of anticonvulsant and antinociceptive agents was also synthesized recently by Góra et al. [58], who designed hybrid derivatives of pyrrolidine-2,5-dione with the thiophene ring, compounds 62a-g and 63a-h (Fig. 15). While compounds 62a-g were obtained by the reaction of 2-(3-methylthiophen-2-yl)succinic acid $\mathbf{6 0}$ with aminoalkylmorpholine or 1-(3-aminopropyl)-4-phenylpiperazine in one step, derivatives 63a-h were obtained in two steps by the reaction of 2-(3-methylthiophen-2-yl) succinic acid 60 with aminoacetic acid to give intermediates 61, which, in turn, underwent the coupling reaction. The best anticonvulsant activity was observed with compound $\mathbf{6 2} \mathbf{b}$, which displayed an $\mathrm{ED}_{50}$ value of $62.14 \mathrm{mg} \mathrm{kg}^{-1}$ in the MES test, compared with references ethosuximide $\left(\mathrm{ED}_{50}>500 \mathrm{mg} \mathrm{kg}^{-1}\right)$ and valproic acid (VPA) $\left(\mathrm{ED}_{50} 252.7 \mathrm{mg} \mathrm{kg}^{-1}\right)$, and $75.59 \mathrm{mg} \mathrm{kg}^{-1}$ in the psychomotor seizure $(6 \mathrm{~Hz})$ test, compared with references ethosuximide $\left(\mathrm{ED}_{50} 221.7 \mathrm{mg} \mathrm{kg}^{-1}\right)$ and VPA $\left(\mathrm{ED}_{50}\right.$ 


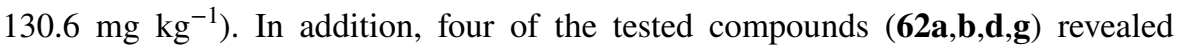
peripheral analgesic activity in the writhing test. In particular, compound $\mathbf{6 2} \mathbf{g}$ was active at a dose of $30 \mathrm{mg} / \mathrm{kg}$, similar to aspirin at the same dose. Compounds $\mathbf{6 2 d}$ and $\mathbf{6 2 \mathrm { g }}$ also showed central analgesic activity in the hot-plate test at a dose of $30 \mathrm{mg} \mathrm{kg}{ }^{-1}$. SAR analysis revealed that the acetamide moiety can extend anticonvulsant activity in both the MES and scPTZ tests.

Later, Obniska et al. [59] expanded the same class of pyrrolidine-2,5-diones by substituting the thiophene ring with an unsubstituted phenyl moiety. The new compounds 66a-m (Fig. 16) were obtained by the condensation of 2-methyl-2-phenyl succinic acid 64 with 3 -aminopropanoic acid to give the intermediate derivatives

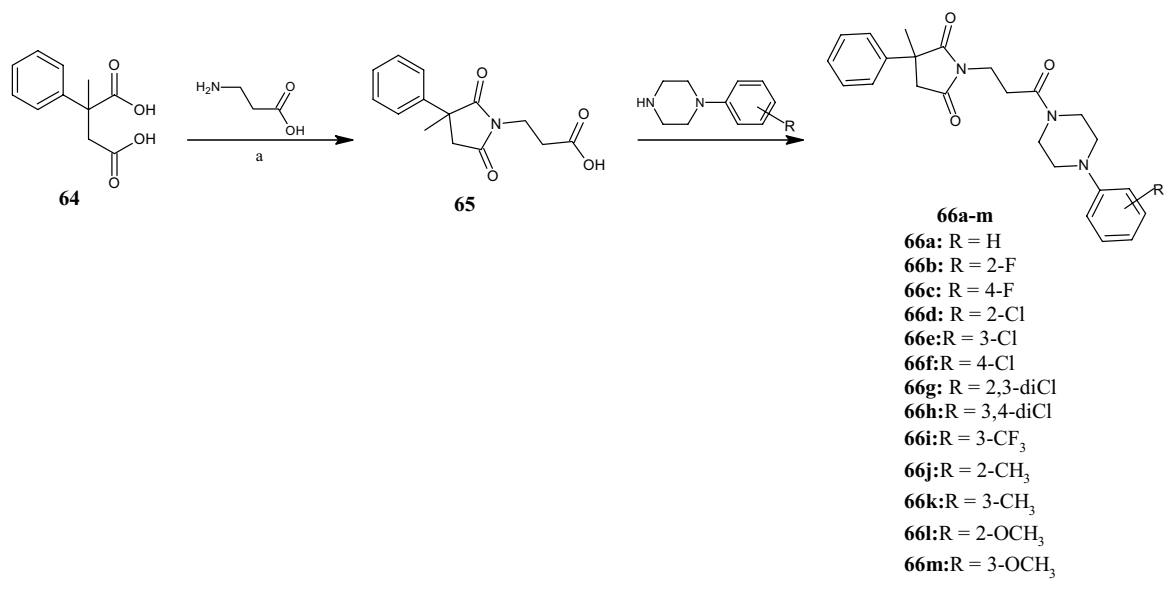

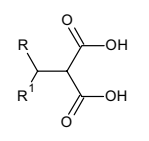

67
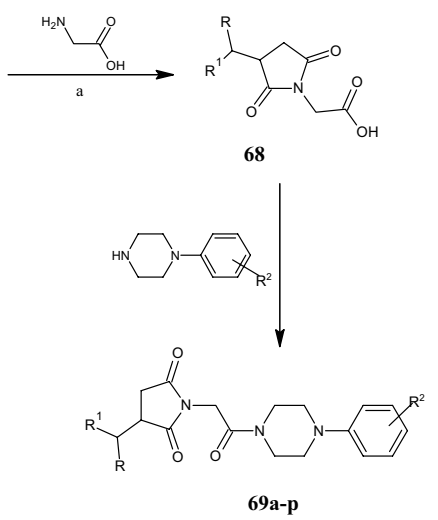

Series $I$
69a: $R, R^{1}=-\mathrm{Ph} ; \mathrm{R}^{2}=2-\mathrm{F}$
69b: $\mathrm{R}, \mathrm{R}^{1}=-\mathrm{Ph} ; \mathrm{R}^{2}=4-\mathrm{F}$
69c: $\mathrm{R}, \mathrm{R}^{1}=-\mathrm{Ph} ; \mathrm{R}^{2}=3-\mathrm{CF}_{3}$
69d: $\mathrm{R}, \mathrm{R}^{1}=-\mathrm{Ph} ; \mathrm{R}^{2}=2-\mathrm{Cl}$
69e: $\mathrm{R}, \mathrm{R}^{1}=-\mathrm{Ph} ; \mathrm{R}^{2}=3-\mathrm{Cl}$
69f: $\mathrm{R}, \mathrm{R}^{1}=-\mathrm{Ph} ; \mathrm{R}^{2}=4-\mathrm{Cl}$
69g: $\mathrm{R}, \mathrm{R}^{1}=-\mathrm{Ph} ; \mathrm{R}^{2}=2,3-\mathrm{diCl}$
69h: $\mathrm{R}, \mathrm{R}^{1}=-\mathrm{Ph} ; \mathrm{R}^{2}=3,4-\mathrm{diCl}$

Series $\mathrm{II}$
69i: $\mathrm{R}=-\mathrm{C}_{2} \mathrm{H}_{5} ; \mathrm{R}^{1}=-\mathrm{CH}_{3} ; \mathrm{R}^{2}=2-\mathrm{F}$
69j: $\mathrm{R}=-\mathrm{C}_{2} \mathrm{H}_{5} ; \mathrm{R}^{1}=-\mathrm{CH}_{3} ; \mathrm{R}^{2}=4-\mathrm{F}$
69k: $\mathrm{R}=-\mathrm{C}_{2} \mathrm{H}_{5} ; \mathrm{R}^{1}=-\mathrm{CH}_{3} ; \mathrm{R}^{2}=3-\mathrm{CF}$
69l: $\mathrm{R}=-\mathrm{C}_{2} \mathrm{H}_{5} ; \mathrm{R}^{1}=-\mathrm{CH}_{3} ; \mathrm{R}^{2}=2-\mathrm{Cl}$
69m: $\mathrm{R}=-\mathrm{C}_{2} \mathrm{H}_{5} ; \mathrm{R}^{1}=-\mathrm{CH}_{3} ; \mathrm{R}^{2}=3-\mathrm{Cl}$
69n: $\mathrm{R}=-\mathrm{C}_{2} \mathrm{H}_{5} ; \mathrm{R}^{1}=-\mathrm{CH}_{3} ; \mathrm{R}^{2}=4-\mathrm{Cl}$
69o: $\mathrm{R}=-\mathrm{C}_{2} \mathrm{H}_{5} ; \mathrm{R}^{1}=-\mathrm{CH}_{3} ; \mathrm{R}^{2}=2,3-\mathrm{diCl}$
69p: $\mathrm{R}=-\mathrm{C}_{2} \mathrm{H}_{5} ; \mathrm{R}^{1}=-\mathrm{CH}_{3} ; \mathrm{R}^{2}=3,4-\mathrm{diCl}$

Fig. 16 General synthetic routes to pyrrolidine-2,5-diones $66 \mathbf{a}-\mathbf{m}$ and $\mathbf{6 9 a}-\mathbf{p}$. Reagents and conditions: $a$ $180{ }^{\circ} \mathrm{C}, 1 \mathrm{~h}$, yields: $68 \%(65), 70 \%\left(68, \mathrm{R}, \mathrm{R}^{1}=\right.$ phenyl $), 36 \%\left(68, \mathrm{R}=\right.$ methyl, $\mathrm{R}^{1}=$ ethyl $)$ 
65, at $180{ }^{\circ} \mathrm{C}$ for $1 \mathrm{~h}$. This structural change did not improve the pharmacological activity compared with the previously mentioned compound $\mathbf{6 2} \mathbf{b}$. However, the

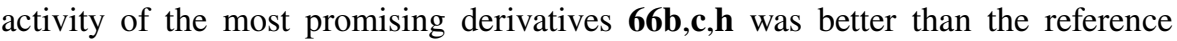
VPA and ethosuximide, both in the MES test with $\mathrm{ED}_{50}$ values of $78.3,83.51$ and $97.67 \mathrm{mg} \mathrm{kg}^{-1}$, respectively, and in the scPTZ test, in which only compound $\mathbf{6 6} \mathbf{b}$ was active $\left(\mathrm{ED}_{50} 114.15 \mathrm{mg} \mathrm{kg}^{-1}\right)$. Finally, in 2021, Góra et al. [60] studied the anticonvulsant properties of two new series of pyrrolidine-2,5-dione-acetamides 69a-p (Fig. 16), exhibiting a benzhydryl or sec-butyl group in position 3 of the pyrrolidine ring. The compounds were synthesized via intermediates $\mathbf{6 8}$, which were obtained by the reaction of succinic acid derivatives 67 with aminoacetic acid at $180{ }^{\circ} \mathrm{C}$ for $1 \mathrm{~h}$. Among the tested compounds, derivative 69k showed the best $\mathrm{ED}_{50}$ values of $80.38 \mathrm{mg} \mathrm{kg}^{-1}$ in the MES and $108.80 \mathrm{mg} \mathrm{kg}^{-1}$ in the $6 \mathrm{~Hz}$ tests, emerging as more effective than VPA. Summarizing the SAR analysis of this class of compounds, the activity appeared to be influenced by the substituent at position 3 of the pyrrolidine2,5-dione ring, as well as the type of phenylpiperazine attached to the acetamide fragment. In particular, the non-aromatic substituent (sec-butyl) in position 3 of the pyrrolidine-2,5-dione ring and the 3-trifluoromethylphenylpiperazine fragment positively affect the anticonvulsant activity as for compound 69k. Slightly less active than compound 69k in the $6 \mathrm{~Hz}$ test was its 2-chlorophenylpiperazine analogue 69l with a 1.2 fold higher $\mathrm{ED}_{50}$ value. On the other hand, the introduction of the benzhydryl group in position 3 of the pyrrolidine-2,5-dione ring and a 4-chloroor 2,3-dichlorophenylpiperazine fragment (compounds 69f and 69g) increased the activity in the scPTZ test (data not shown).

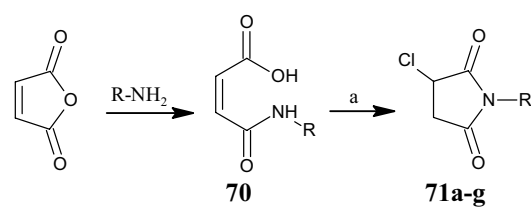

71a: $\mathrm{R}=4-\mathrm{C}_{2} \mathrm{H}_{5}$-phenyl
71b: $\mathrm{R}=2,4,6$-triCH $\mathrm{H}_{3}$-phenyl
71c: $\mathrm{R}=$ naphthalen-1-yl
71d: $\mathrm{R}=4-\mathrm{CF}_{3}$-quinolin-5-yl
71e: $\mathrm{R}=4$-benzoic acid
71f: $\mathrm{R}=3$-benzoic acid
71g: $\mathrm{R}=4-\mathrm{CN}$-phenyl
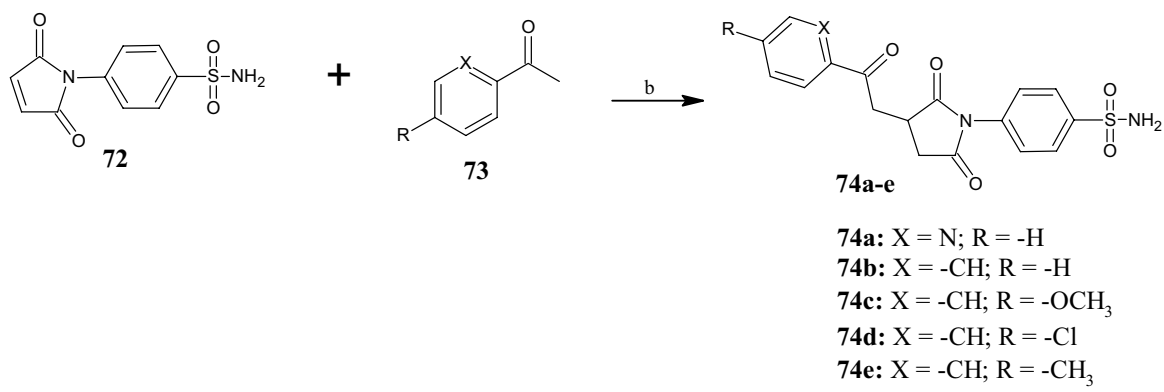

Fig. 17 General synthesis of pyrrolidine-2,5-diones 71a-g and 74a-e. Reagents and conditions: $a \mathrm{SOCl}_{2}$, under reflux, 5-8 h, yields: 83-96\%; $b$ OtBU-L-threonine, 1,8-diazabicyclo[5.4.0]undec-7-ene (DBU), chloroform $\left(\mathrm{CHCl}_{3}\right)$, r.t., yields: $51.3-63.2 \%$ 
Pyrrolidine-2,5-dione is a versatile scaffold, as demonstrated by Oktay et al. [61] who prepared a series of 3-chloro-1-aryl pyrrolidine-2,5-diones evaluated for their inhibitory activity on the human physiologically relevant carbonic anhydrase (CA) isoenzymes hCA I and hCA II. Both isoenzymes are involved in several diseases, such as retinal and cerebral edema, glaucoma, and epilepsy. Therefore, their inhibition could be useful to counteract these issues. The synthetic route to obtain the 3-chloro- $N$-aryl pyrrolidine-2,5-dione derivatives 71a-g (Fig. 17) started with the reaction between maleic anhydride and aromatic amines, with consequent opening of the ring to yield (Z)-4-oxo-4(arylamino)but-2-enoic acid 70, which, in turn afforded compounds 71a-g by reaction with thionyl chloride $\left(\mathrm{SOCl}_{2}\right)$ under reflux. All 3-chloro-1-aryl pyrrolidine-2,5-diones, except compound 71e, were able to inhibit hCA I ( $K_{\mathrm{i}}$ in the range of $23.27-36.83 \mathrm{nM})$ and hCA II ( $K_{\mathrm{i}}$ in the range of 10.64 and $23.34 \mathrm{nM}$ ) with higher or comparable activity than the reference hCA inhibitor acetazolamide (AZA) (hCA I: $K_{\mathrm{i}}=34.70 \mathrm{nM}$; hCA II: $K_{\mathrm{i}}=31.93 \mathrm{nM}$ ). The most active compounds were derivatives 71d (hCA I: $K_{\mathrm{i}}=23.27 \mathrm{nM}$ ) and 71c (hCA II: $K_{\mathrm{i}}=10.64 \mathrm{nM}$ ), both decorated at the pyrrolidine-2,5-dione nitrogen atom with bicyclic scaffolds, such as quinoline and naphthalene.

As reported in the literature, cyclic imides, such as pyrrolidine-2,5-diones, possess interesting pharmacological properties due to the ability of the imide group to facilitate the crossing of biological membranes. Recently, Jan et al. [62] synthesized a series of pyrrolidine-2,5-dione derivatives 74a-e (Fig. 17) as multitarget anti-inflammatory agents by applying a synthetic strategy based on Michael additions of ketones $\mathbf{7 3}$ to $N$-substituted maleimide 72, at room temperature in the presence of $\mathrm{O} t \mathrm{BU}$-L-threonine and 1,8-diazabicyclo[5.4.0] undec7-ene (DBU), using a self-assembled three-component system as organocatalyst. Biological activity was determined by in vitro assays, such as cyclooxygenase- 1 (COX-1), cyclooxygenase-2 (COX-2), and 5-lipoxygenase (5-LOX), albumin denaturation and anti-protease assays, and in vivo in mice. In the in vitro assays, all compounds showed marked COX-2 inhibition compared with the reference diclofenac $\left(\mathrm{IC}_{50}=10.05 \mu \mathrm{M}\right)$ with $\mathrm{IC}_{50}$ values in the range of 0.98 and $8.94 \mu \mathrm{M}$. The most potent compound was 74e, which showed selectivity for COX-2 over COX-1, with a selectivity index value $(\mathrm{SI})\left[\mathrm{SI}=\mathrm{IC}_{50}(\mathrm{COX}-1) / \mathrm{IC}_{50}\right.$ $(\mathrm{COX}-2)]$ of 31.5 . In contrast, the SI values of compounds $\mathbf{7 4 a - d}$ were 4.88 , 11.5, 18.7 and 10.9, respectively. Furthermore, aryl ketone derivatives $\mathbf{7 4 a}$ and 74e showed excellent inhibition of human 5-LOX with $\mathrm{IC}_{50}$ values of 0.81 and $0.86 \mu \mathrm{M}$, respectively, which were slightly higher than the standard drug zileuton $\left(\mathrm{IC}_{50}=0.63 \mu \mathrm{M}\right)$. Finally, compound $\mathbf{7 4 a}$ also induced albumin denaturation $\left(\mathrm{IC}_{50}=5.36\right)$ and protease inhibition $\left(\mathrm{IC}_{50}=13.39 \mu \mathrm{M}\right)$. The in vivo test with the most promising compounds $\mathbf{7 4 a}$ and $\mathbf{7 4} \mathbf{e}$ revealed anti-inflammatory activity, which was ascertained with various mediators like histamine, bradykinin, prostaglandin and leukotriene. In addition, the same compounds showed safety in an acute toxicity study, in which the lethal dose $\left(\mathrm{LD}_{50}\right)$ of both compounds in the experimental mice was approximately $1000 \mathrm{mg} / \mathrm{kg}$. The SAR analysis revealed that the para-substituent on the phenyl ketone influences the biological activity. However, the replacement of the aryl ketone at position 3 of the 


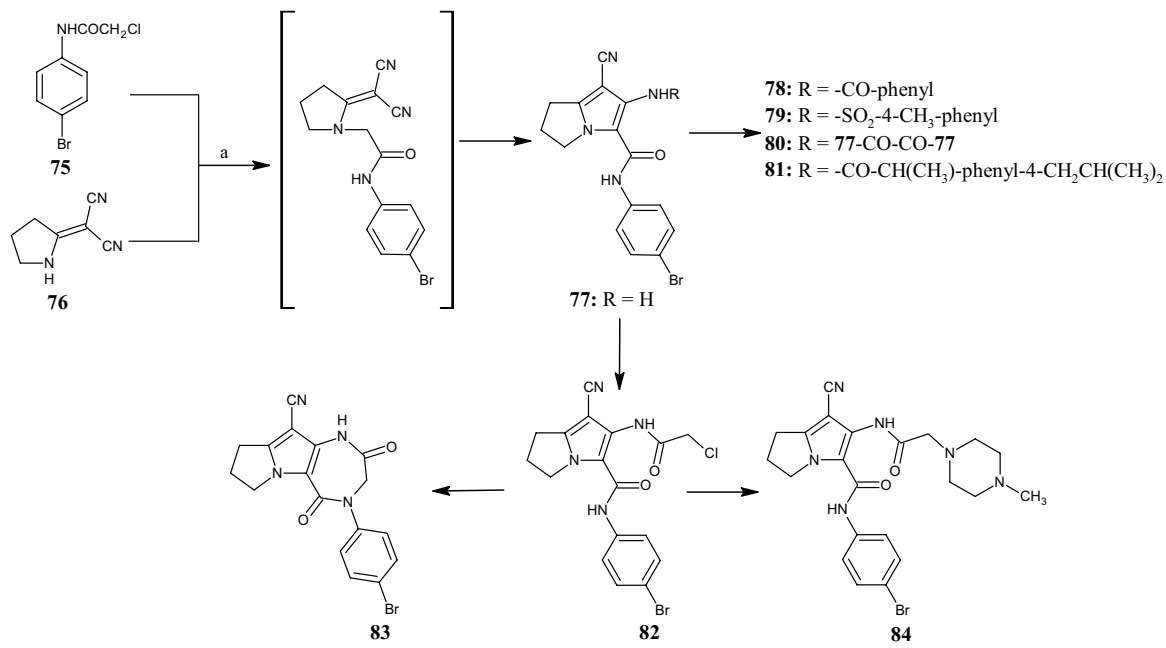

Fig. 18 General synthetic scheme to pyrrolizine carboxamide derivatives 77-84. Reagents and conditions: $a \mathrm{~K}_{2} \mathrm{CO}_{3}$, acetone, under reflux, $24 \mathrm{~h}$, yields: $68 \%$ (77)

pyrrolidine-2,5-dione nucleus with oxocycloalkyl/oxoalkyl groups (structure not shown) was detrimental to the anti-inflammatory properties.

\subsection{Pyrrolizines Obtained by Cyclizations}

In 2016, Gouda et al. [63] designed and synthetized a new series of pyrrolizine carboxamides 77-84 (Fig. 18) as dual cyclooxygenase (COX) and 5-LOX inhibitors with safer gastric profile. Pyrrolizine 77 was synthesized via the intramolecular cyclization of an intermediate obtained by reacting $N$-(4-bromophenyl)2-chloroacetamide $\mathbf{7 5}$ with 2-(pyrrolidin-2-ylidene)malononitrile $\mathbf{7 6}$ under reflux in acetone for $24 \mathrm{~h}$, and was used as starting material for the synthesis of derivatives 78-84. All pyrrolizines were assayed for anti-inflammatory activity and showed $\mathrm{IC}_{50}$ values of 2.45-5.69 $\mu \mathrm{M}$ and $0.85-3.44 \mu \mathrm{M}$ for COX-1 and COX-2, respectively. Furthermore, compound 77 exhibited higher anti-inflammatory and analgesic activities compared with ibuprofen. Upon $\mathrm{NH}_{2}$-acylation, its analogues, such as the 2-chloroacetyl (82) and the benzoyl derivative (78) were obtained. Introduction of the 4-tolylsulfonyl moiety into compound $\mathbf{7 9}$ further improved both biological activities. Conversely, the hybrid compound 81, composed of the pyrrolizine precursor $\mathbf{7 7}$ and ibuprofen, did not show antiinflammatory activity and only a weak analgesic effect. 4-Methylpiperazine derivative 84, the diazepine derivative 83, and the dimer $\mathbf{8 0}$ showed lower anti-inflammatory and analgesic activities. Nevertheless, compounds $\mathbf{7 8}$ and $\mathbf{8 1}$ revealed better safety profiles than ibuprofen in acute ulcerogenicity and histopathological studies. Docking studies into COX-1 (PDB ID: 1EQG), COX-2 (PDB ID: 1CX2) and 5-LOX (PDB ID: 
3O8Y, 3V99) showed that compound 79 fits well into the active sites of COX-1 and COX-2, whereas compound $\mathbf{7 9}$ exhibits the highest binding affinity for 5-LOX.

\section{Pyrrolidine Derivatives from Commercial Building Blocks}

\subsection{Pyrrolidines from Proline}

The interest in the pyrrolidine nucleus as skeleton of molecules with biological potential is endorsed by its similarity to the non-essential L-proline amino acid, which is used to obtain molecules with a specific stereochemistry. In 2017, Pannala et al. [64] developed a metal- and catalyst-free three-component decarboxylative coupling reaction of proline, aldehydes and 4-hydroxycarbazole to access pyrrolidinyl-carbazole derivatives $\mathbf{8 5 a - p}$ (Fig. 19) with antiproliferative and antioxidant activities. The antiproliferative activity was evaluated by in vitro assays on three different cancer cell lines (MCF-7, MDA-MB-231, and lung cancer cells A549) and the results were compared with those obtained with the positive control doxorubicin. Overall, compounds $\mathbf{8 5 b , c , k , p}$ showed the best cytotoxic activity against MCF-7 cells $\left(\mathrm{IC}_{50} 8.3-16.4 \mu \mathrm{M}\right.$ ), whereas compound $\mathbf{8 5 p}$ was also able to reduce the growth
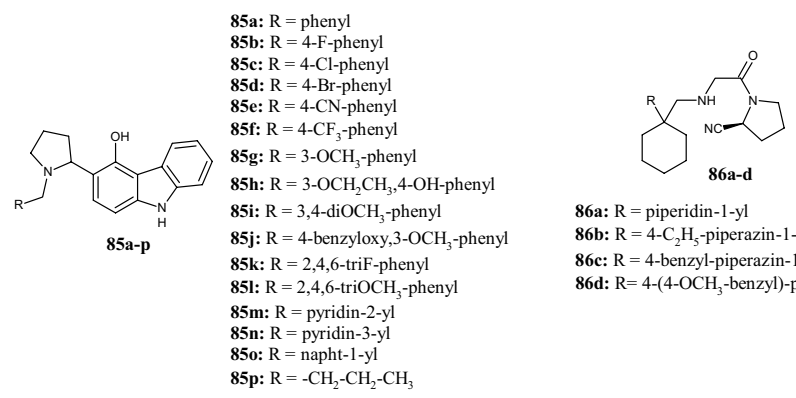

86a: $\mathrm{R}=$ piperidin-1-yl

86b: $\mathrm{R}=4-\mathrm{C}_{2} \mathrm{H}_{5}$-piperazin-1-yl

86c: $R=4$-benzyl-piperazin-1-yl

86d: $\mathrm{R}=4-\left(4-\mathrm{OCH}_{3}-\right.$ benzyl)-piperazin-1-yl
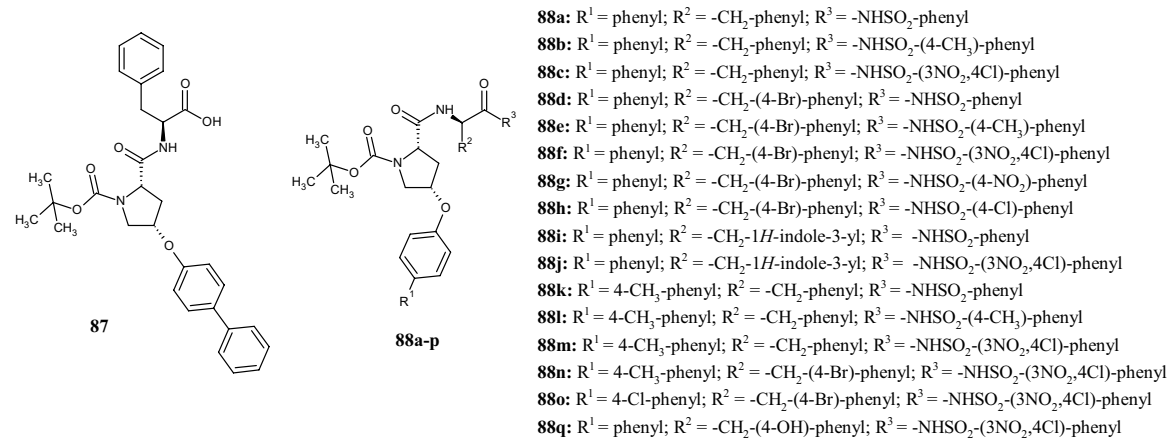

Fig. 19 Molecular structures of pyrrolidinyl-carbazole derivatives 85a-p, pyrrolidine-2-carbonitriles 86a-d, Mcl-1 inhibitor 87, and pyrrolidine-1-carboxylates 88a-p 


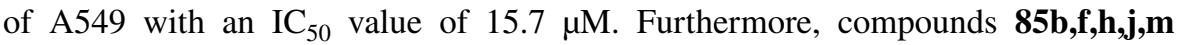
showed higher radical scavenging abilities than ascorbic acid $\left(\mathrm{IC}_{50} 40.9 \mu \mathrm{M}\right)$, with the best results displayed by compound $85 \mathbf{h}\left(\mathrm{IC}_{50}=27 \mu \mathrm{M}\right)$ due to the presence of the hydroxy group on the phenyl ring. Docking analysis in the colchicine binding site (PDB ID: 1SA0) indicated that a methoxy-benzyloxy moiety $(\mathbf{8 5 j})$ and a trifluoromethyl group (85f) on the phenyl ring participate in hydrophobic binding interactions with several amino acid residues. Halogenated compounds $\mathbf{8 5 b}-\mathbf{d}, \mathbf{k}$ displayed similar binding modes in the tubulin active site. Finally, a bulky naphthyl ring (85o) reduced the binding affinity.

The use of proline for the synthesis of pyrrolidine derivatives was also a strategic path for Nabil Aboul-Enein et al. [65], who synthesized a small class of antidiabetic compounds. The (S)-1-[(cyclohexylmethyl)glycyl]pyrrolidine-2-carbonitriles 86a-d obtained (Fig. 19) were biologically evaluated for inhibitory activity toward dipeptidyl peptidase-4 (DPP4), a serine exopeptidase belonging to the S9B protein family, which cuts X-proline dipeptides from the N-terminus of polypeptides, such as chemokines, neuropeptides, and peptide hormones. As DPP4 is known to inactivate the incretin glucagon-like peptide-1 (GLP-1), the discovery of new DPP4 inhibitors is considered an indirect approach to increase GLP-1 levels and thus to manage diabetes mellitus type 2 . The starting point for the synthesis of derivatives 86a-d was (2S)-1-(chloroacetyl)pyrrolidine-2-carbonitrile, which could be obtained from $S$-proline via a chloroacetylation followed by an amidation of its carboxylate group and a final dehydration. The ability of compounds 86a-d to inhibit the DPP4 enzyme was studied in diabetic mice that received the compounds orally at a dose of $100 \mathrm{mg} / \mathrm{kg}$ and the results were compared with those of the control group that received vildagliptin at the same dose. Serum DPP4 inhibition was evaluated $3 \mathrm{~h}$

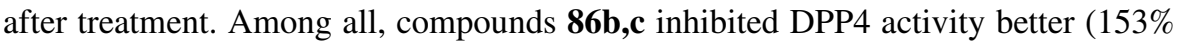
and $138 \%$, respectively) than the control group (114\%). In contrast, replacement of the piperazine ring with piperidine (86a) or (4-methoxybenzyl)piperazine (86d) reduced DPP4 inhibition to $85 \%$ and $105 \%$, respectively. Docking studies confirmed a good binding affinity of compounds $\mathbf{8 6 \mathbf { b } , \mathbf { c }}$ in the active site of DPP4 (PDB ID: 3 W2T) in agreement with their anti-diabetic activity.

Starting from $(2 S, 4 R)$-4-hydroxyproline, Wan et al. [66] designed and synthesized a new series of pyrrolidine derivatives based on compound 87, which was described as potent inhibitor of myeloid cell leukemia-1 (Mcl-1) protein $\left(K_{\mathrm{i}}=8.4 \mu \mathrm{M}\right)$ (Fig. 19). Using a fluorescence polarization assay (FPA), these authors observed that the most potent compounds 88a-p were characterized by phenyl groups at $R^{1}$, aromatic or heteroaromatic rings at $\mathrm{R}^{2}$, and different benzenesulfonamides at $\mathrm{R}^{3}$. Compounds $88 \mathrm{c}$ and $\mathbf{8 8 f}$ showed the best binding affinities towards Mcl-1, with $K_{\mathrm{i}}$ values of 0.94 and $0.53 \mu \mathrm{M}$, respectively, slightly higher than the positive control gossypol $\left(K_{\mathrm{i}}=0.39 \mu \mathrm{M}\right)$ but very much lower than compound 87 . The replacement of phenyl or 4-bromophenyl at $\mathrm{R}^{2}$ with 3-indolyl and p-hydroxyphenyl $(\mathbf{8 8 i}, \mathbf{j}, \mathbf{p})$ was unfavorable for the biological activity. Finally, the replacement of the benzensulfonamide moiety with a hydroxy group and the introduction of linear chains or substituted phenyls instead of the 4-bromobenzyl group (structures not shown) resulted in the loss of binding affinity toward the Mcl-1 protein $\left(K_{\mathrm{i}}>10 \mu \mathrm{M}\right)$. Moreover, compound 88f exhibited good antiproliferative activities against MDA-MB-231, PC-3 (prostate 

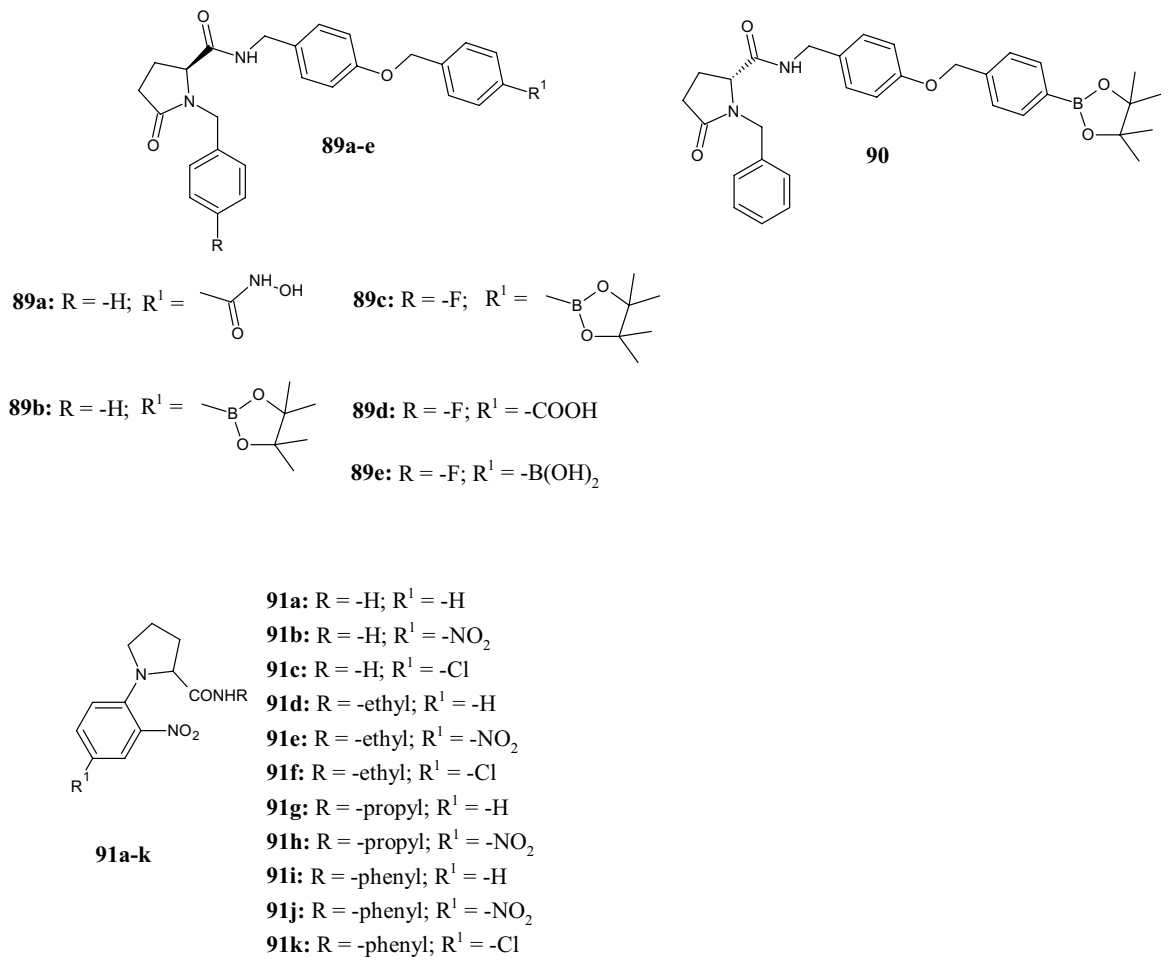

Fig. 20 Molecular structures of pyroglutamic acid derivatives 89a-e and 90 and $N$-(2'-nitrophenyl)pyrrolidine-2-carboxamides 91a-k

cell cancer), and $\mathrm{K} 562$ (chronic myeloid leukaemia) cell lines with $\mathrm{IC}_{50}$ values of $13.6,10.7$, and $23.0 \mu \mathrm{M}$, respectively.

In 2020, Gerokonstantis et al. [67] synthesized compounds 89a-e and 90 (Fig. 20), which are potent inhibitors of autotaxin (ATX), a glycoprotein responsible for the hydrolysis of lysophosphatidylcholine (LPC) into bioactive lipid lysophosphatidic acid (LPA), whose upregulation is involved in pathological inflammatory conditions. The main scaffolds of the new derivatives were the natural amino acid $S$-proline, the naturally derived $S$-pyroglutamic acid ((2S)-5-oxopyrrolidine-2-carboxylic acid), and their enantiomers. In both cases, the new derivatives possess a benzyl type substituent at the pyrrolidine nitrogen, while the carboxylic group at position 5 is coupled to side chain via an amide bond containing a benzyl-ether type substituent, which bears carboxylate, methyl ester, sulfonamide, boronic ester, imidazole, hydroxamate, tetrazole, triazol, pyridine and boronic acid moieties in para-position (structures not shown). The in vitro assay showed that the pyroglutamic acid derivatives, including hydroxamic acid 89a $\left(\mathrm{IC}_{50} 700 \mathrm{nM}\right)$ and boronic acid derivatives $89 \mathrm{~b}\left(\mathrm{IC}_{50} 50 \mathrm{nM}\right), 89 \mathrm{c}\left(\mathrm{IC}_{50} 120 \mathrm{nM}\right)$, $90\left(\mathrm{IC}_{50} 180 \mathrm{nM}\right)$, and $89 \mathrm{e}\left(\mathrm{IC}_{50} 35 \mathrm{nM}\right)$ were the most active compounds against 
the ATX enzyme, whereas only one out of six compounds-the carboxylic acid derivative $89 \mathbf{d}$ - was the least active ( $\left.\mathrm{IC}_{50} 800 \mathrm{nM}\right)$.

Antimicrobial peptides (AMPs) are small peptides with a wide range of inhibitory effects against bacteria and other pathogens. Pyrrhocoricin, apidaecin and drosocin are some examples of proline-rich antibacterial peptide family members able to bind the bacterial DnaK protein. In 2020, Odusami et al. [68] reported the synthesis of novel $\mathrm{N}$-(2'-nitrophenyl)pyrrolidine-2-carboxamides 91a-k (Fig. 20) with the aim of searching for amino acid analogues with antibacterial properties capable of mimicking antimicrobial peptides. The main structural features of compounds 91a-k were the simultaneous presence of (1) a hydrophobic group provided by the phenyl ring, and (2) a cationic charge given by the amino group after its protonation, (3) different $N^{\prime}$-substituents introduced to study the effect of conformational flexibility on the antimicrobial activity. The activity was evaluated both against Gram-positive [Bacillus subtilis (ATCC 19659), Enterococcus faecalis (ATCC 14506), Mycobacterium smegmatis (ATCC 14468), Staphylococcus epidermidis (ATCC 12228) and Staphylococcus aureus (ATCC 25923)] and Gram-negative [Enterobacter cloacae (ATCC 13047), Escherichia coli (ATCC 25922), Proteus vulgaris (ATCC 33420), Klebsiella oxytoca (ATCC 8724) and Proteus mirabilis (ATCC 7002)] bacterial strains, and the results were compared with those of reference compounds streptomycin and nalidixic acid. As assessed by the minimum inhibitory concentration (MIC) values, all the carboxamides $91 \mathbf{a}-\mathbf{k}$ were more potent against $S$. aureus and E. cloacae than the standard streptomycin $(256 \mu \mathrm{g} / \mathrm{ml}$ and $>512 \mu \mathrm{g} / \mathrm{ml}$, respectively), with compounds 91b $(15.6 \mu \mathrm{g} / \mathrm{ml}), 91 \mathrm{c}$ and 91k $(62.5 \mu \mathrm{g} / \mathrm{ml}$ for both) being most potent against $S$. aureus, and compounds $91 \mathrm{c}(62.5 \mu \mathrm{g} / \mathrm{ml})$ and $91 \mathbf{j}(31.3 \mu \mathrm{g} / \mathrm{ml})$ being most potent against E. cloacae. Furthermore, the MIC values of compounds 91a-k were lower than those found with nalidixic acid $(\geq 500 \mu \mathrm{g} / \mathrm{ml})$ against $E$. faecalis, M. smegmatis, E. coli, and P. vulgaris (MIC $\leq 250 \mu \mathrm{g} / \mathrm{ml}$ ). Conversely, for other strains, the MICs of the carboxamides were higher than the ones of the reference compounds. SAR investigation showed that, in consideration of the $N^{\prime}$ substituents, antibacterial activity increased in the order: $N^{\prime}$-Et $(\mathbf{9 1 d - f})<N^{\prime}-\mathrm{H}$ $(91 a-c)<N^{\prime}-\operatorname{Pr}(\mathbf{9 1 g}, \mathbf{h})<N^{\prime}-\mathrm{Ph}(\mathbf{9 1 i}-\mathbf{k})$, whereas with the $4^{\prime}$-phenyl substituents, the activity increased in the order: $4^{\prime}-\mathrm{PhH}\left(\mathbf{9 1 a , d , g , i )}<4^{\prime}-\mathrm{PhCl}\right.$ (91c and 91f $)<4^{\prime}-\mathrm{PhNO}_{2}(\mathbf{9 1 b}, \mathbf{e}, \mathbf{h})$ except for the $N^{\prime}$-phenyl carboxamides $91 \mathbf{i}-\mathbf{9 1 k}$, where 91k $\left(4^{\prime}-\mathrm{Cl}\right)>91 \mathbf{j}\left(4^{\prime}-\mathrm{NO}_{2}\right)>91 \mathbf{i}\left(4^{\prime}-\mathrm{H}\right)$.

\subsection{Derivatives from Other Preformed Pyrrolidine Scaffolds}

Given the interest of the scientific community in the pyrrolidine nucleus, many chemical industries have synthesized variously substituted pyrrolidines as building blocks for new drugs. Among these, pyrrolidine, pyrrolidin-2-one, pyrrolidine2,5-dione, and prolinol scaffolds are very useful preformed rings for the synthesis of new bioactive compounds.

Beta-secretase 1 (BACE1) is the enzyme responsible for the proteolytic processing of the amyloid precursor protein (APP), which leads to the generation of 


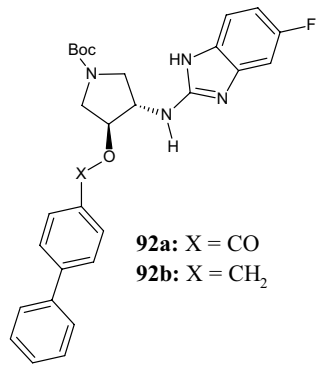

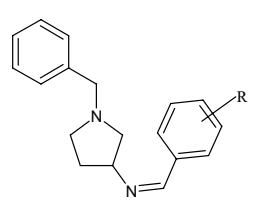

93a-o

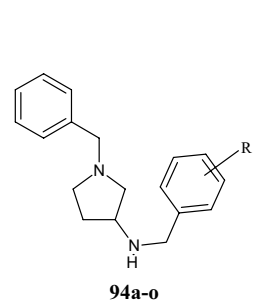

93-94a: $\mathrm{R}=-\mathrm{H}$

93-94b: $\mathrm{R}=-2,3-\mathrm{diOCH}_{3}$

93-94c: $\mathrm{R}=-3,4,5-\mathrm{triOCH}_{3}$

93-94d: $\mathrm{R}=-4-\mathrm{OH}$

93-94e: $\mathrm{R}=-2-\mathrm{OH}$

93-94f: $\mathrm{R}=-2,4-\mathrm{diOH}$

93-94g: $\mathrm{R}=-3-\mathrm{CH}_{3}$

93-94h: $\mathrm{R}=-4-\mathrm{CH}_{3}$

93-94i: $\mathrm{R}=-4-\mathrm{NO}_{2}$

93-94j: $\mathrm{R}=-4-\mathrm{CF}_{3}$

93-94k: $\mathrm{R}=-4-\mathrm{OCF}_{3}$

93-94l: $\mathrm{R}=-4-\mathrm{Cl}$

93-94m: $\mathrm{R}=-4-\mathrm{F}$

93-94n: $\mathrm{R}=-4-\mathrm{Br}$

93-940: $R=-2,4-d i F$
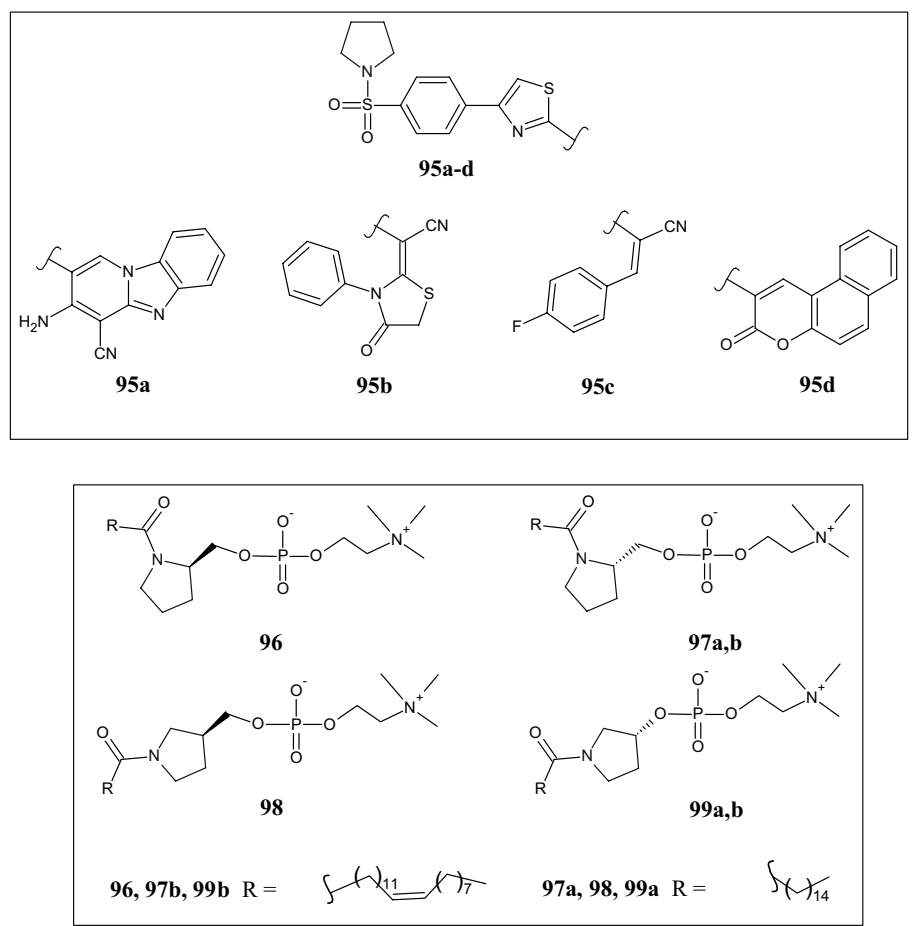

Fig. 21 Molecular structures of pyrrolidine derivatives 92a,b, Schiff bases 93a-o and their reduced counterparts $\mathbf{9 4 a - o}$, benzenesulfonylpyrrolidines $\mathbf{9 5 a - d}$, and pyrrolidine-based 3-deoxysphingomyelins 96, 97a,b, 98, 99a,b

amyloid- $\beta$ (A $\beta$ ) peptides. The aggregation of $A \beta$ in the brain of patients is responsible for the onset of Alzheimer's disease (AD). Therefore, the development of treatments towards BACE1 could be a good strategy to fight this devastating neurodegenerative disease. In 2016, De Tran et al. [69] synthesized a library of $(3 S, 4 S)$ 4-aminopyrrolidine-3-ol derivatives 92a,b (Fig. 21) as potential anti-AD agents with a target selectivity toward BACE1. An in vitro inhibition assay of BACE1 showed that compound 92a was the most active, with an $\mathrm{IC}_{50}$ value of $0.05 \mu \mathrm{M}$. However, when replacing the carbonyl group of 92a with a methylene unit as in the compound 
92b, the inhibition of BACE1 was approximately two times lower $\left(\mathrm{IC}_{50}=0.12 \mu \mathrm{M}\right)$. Unexpectedly, the opposite was observed in the cell-based assay, where compound 92b was more effective than compound 92a, most probably due to a difference in cell permeability $\left(\mathrm{IC}_{50}\right.$ values 1.7 versus $40 \mu \mathrm{M}$, respectively). Boc-deprotected derivatives having the pyrrolidine nitrogen atom unsubstituted or substituted with alkyl, acyl or sulfonyl groups were less active (structures not shown). A molecular docking study confirmed interactions with the BACE1 active site.

Novel compounds for the treatment of Alzheimer's disease were also investigated by Choubey et al. [70], who synthesized multitargeted molecular hybrids of $\mathrm{N}$-benzyl pyrrolidine derivatives, like imines 93a-o and their reduced counterpart 94a-o (Fig. 21). All compounds were studied for their inhibitory activity towards of cholinesterases (AChE and BChE) and BACE-1 in order to evaluate their multitarget profile. Overall, derivatives 94a-o inhibited both cholinesterases as well as BACE-1 with greater potency than Schiff bases 93a-0. SAR studies revealed that electron donating groups (EDGs) at the terminal phenyl ring elicit less potency with respect to acetylcholinesterase (AChE) inhibition than EWGs. Thus, derivatives bearing an EWG exhibited $\mathrm{IC}_{50}$ values of less than $1 \mu \mathrm{M}$, as observed for compounds 94k $(0.058 \mu \mathrm{M})$ and $940(0.069 \mu \mathrm{M})$, which were found to be almost as active as the reference donepezil $(0.042 \mu \mathrm{M})$. A similar trend was observed for butyrylcholinesterase (BChE) inhibition. All the Schiff bases, with the exception of the compound $\mathbf{9 3} \mathbf{j}$ containing a $4-\mathrm{CF}_{3}$ group, showed a moderate inhibitory effect, whereas, among compounds 94a-o, substitution with EWGs gave excellent BACE-1

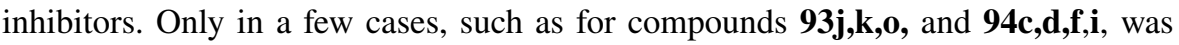
the intended multitarget profile not observed.

Anticancer activity of pyrrolidine derivatives was studied by Bashandy et al. [71], who synthetized a new series of compounds characterized by the presence of a benzenesulfonylpyrrolidine moiety bearing a variously substituted 1,3-thiazole ring in position 4 of the phenyl ring. All compounds were tested for their in vitro antiproliferative activity against MCF-7 cells. Only a few compounds, namely 95a (benzo[4,5]imidazo[1,2-a]pyridine), 95b ((4-oxo-3-phenyl-1,3-thiazolidin2-ylidene)ethanenitrile), 95c ((4-fluorophenyl)-acrylonitrile), and 95d (benzo[f] chromen-3-one) (Fig. 21), exhibited a slight improved activity compared to doxorubicin $\left(\mathrm{IC}_{50}=68.6 \mu \mathrm{M}\right)$, with $\mathrm{IC}_{50}$ values of $49.11,48.01,49.78$ and $49.27 \mu \mathrm{M}$, respectively. In addition, molecular docking studies confirmed their ability to bind the DHFR active site (PDB ID: 4DFR).

In 2019, Hassan et al. [72] synthesized a series of pyrrolidine-based 3-deoxysphingomyelin analogues carrying various acyl chains (palmitoyl, palmitoleoyl, oleoyl, erucoyl, linoleoyl, and $\alpha$-linolenoyl) at the pyrrolidine nitrogen atom and evaluated the compounds as antitumor agents against a panel of cancer cell lines including breast, non-small-cell lung, liver, and skin cancers. The most promising compounds were characterized by erucoyl $(96,97 b, 99 b)$ or palmitoyl $(97 \mathbf{a}, 98$, 99a) chains (Fig. 21). The best results were obtained for MCF-7 cells, which were more sensitive to the treatment with compounds $96,97 \mathbf{b}$, and $99 \mathbf{b}$, eliciting $\mathrm{GI}_{50}$ values at the micromolar level $(15.7-24.8 \mu \mathrm{M})$. This effect was also confirmed in their study on the inhibition of Akt phosphorylation. In fact, compounds 97a, 98, and 99a bearing identical acyl chains but exhibiting different stereochemistry, were 

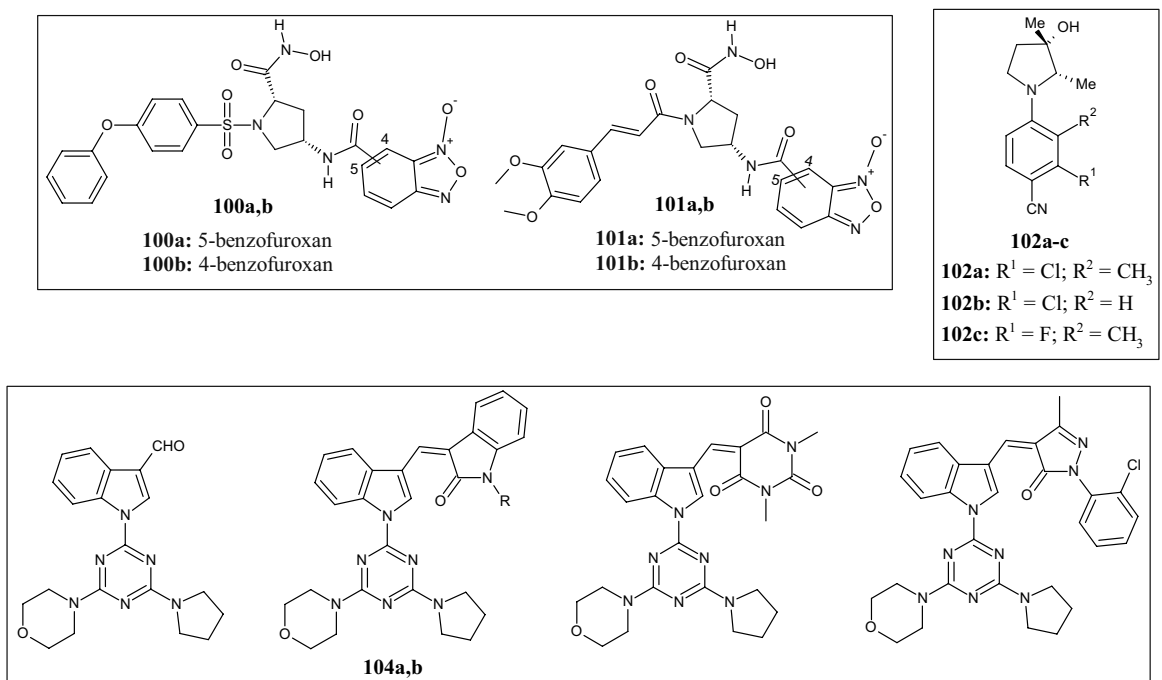

103

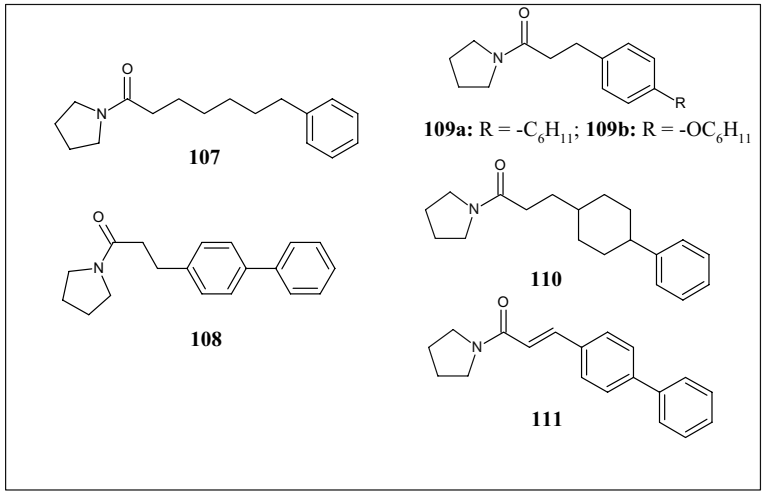

Fig. 22 Molecular structures of hybrid benzofuroxan-based pyrrolidine hydroxamates 100a,b and 101a,b, pyrrolidine benzonitriles 102a-c, hybrid pyrrolidine derivatives 103, 104a,b, 105, 106, and pyrrolidine amides 107, 108, 109a,b, 110, 111

equally active, with $\mathrm{GI}_{50}$ values of $21.1,26.4$, and $32.5 \mu \mathrm{M}$, respectively, confirming the stereochemistry as irrelevant for activity. Molecular docking studies established that the interaction with Akt (PDB ID: 3096) may be the predominant mechanism of action of the 3-deoxysphingomyelin analogues tested.

In 2018, Zhang et al. [73] synthesized new hybrid benzofuroxan-based pyrrolidine hydroxamates carrying on the pyrrolidine nitrogen atom two different substituents: a 3-phenoxybenzenesulfonyl (100a,b) or a (3,4-dimethoxyphenyl)prop-2enoly (101a,b) moiety (Fig. 22). All compounds elicited antiproliferative activity against several tumor cell lines, including A549, ES-2 (ovarian clear carcinoma cell), HeLa (cervix carcinoma), K562, MCF-7, and MDA-MB-231 ( IC $_{50}$ values of 3.56-25.64 $\mu \mathrm{M})$, as well as NO-releasing capability $(25.51-34.43 \mu \mathrm{M} / \mathrm{l})$. The 
anticancer activity was ascribed to the inhibition of matrix metalloproteinases 2 and 9 (MMP-2 and MMP-9), as indicated by the reduced proteolytic activity after their isolation from treated cells. Among the phenoxybenzenesulfonamides, the 5-benzofuroxan 100a showed higher MMP-2 and -9 inhibitory activity $\left(\mathrm{IC}_{50}\right.$ values of 102 and $162 \mathrm{nM}$, respectively) than the 4-benzofuroxan analog $\mathbf{1 0 0 b}$ ( $\mathrm{IC}_{50}$ values of 182 and $242 \mathrm{nM}$, respectively), whereas the (3,4-dimethoxyphenyl)prop-2-enamide5-benzofuroxan (101a) and the 4-benzofuroxan (101b) were less effective $\left(\mathrm{IC}_{50}\right.$ values of 345-524 nM). Docking studies carried out in the active site of MMP-2 (PDB ID: $1 \mathrm{HOV}$ ) with compound 101a highlighted the ability of the hydroxamate group to chelate the catalytic zinc ion and both arylsulfonyl and benzofuroxan groups to create hydrogen bonds with amino acid residues.

Although polyhydroxylated pyrrolidines are important scaffolds of molecules for the treatment of metabolic diseases [52, 54], hydroxy groups could be subject to oxidation and conjugation reactions that would make the molecules metabolically unstable. In this regards, with the aim of modifying the pharmacokinetic profile, Asano et al. [74] synthesized 4-(pyrrolidin-1-yl)benzonitrile derivatives 102a-c (Fig. 22) as selective androgen receptor modulators (SARMs) by optimizing the structure of previously reported 1-(4-cyano-1-naphthyl)-2,3-disubstituted pyrrolidine derivatives [75]. In particular, they introduced a methyl group at C-3 of the pyrrolidine ring that, due to its steric hindrance, should prevent metabolic instability, conferring better pharmacokinetic (PK) profiles than the parent 3-hydroxy compounds. Compounds 102b,c had low cLogP values $(<3)$, showed better metabolic stability, and retained potent androgen receptor (AR) agonistic activity. In addition, 2-chlorobenzonitrile 102b and 3-fluoro-2-methylbenzonitrile 102c derivatives showed good bioavailability values (53.4 and $46.3 \%$, respectively) and strong anabolic activity in levator ani muscle (>300\%), which was dose-dependent as demonstrated by in vivo studies on rats after oral administration. The X-ray co-crystal structure of 102c bound to the AR LBD (PDB: 5T8J) highlighted a binding mode almost identical to that of the previously studied $(2 S, 3 S)$-2-methyl-3-hydroxylpyrrolidine-2-chloro-3-methylbenzonitrile [75].

In 2018, Kaur et al. [76] designed and synthesized a library of hybrid molecules by combining triazine-indole with morpholine/piperidine/pyrrolidine and pyrazole/pyrimidine/oxindole moieties, as novel anti-inflammatory agents. All compounds were tested for inhibition of COX-1 and COX-2 and the results were compared with that of diclofenac, a COXs non-selective inhibitor, and celecoxib, a potent and selective COX-2 inhibitor. Of all compounds tested, pyrrolidine derivatives 103,104a,b,105,106 (Fig. 22) inhibited $\mathrm{COX}-2$ with $\mathrm{IC}_{50}$ values in the range of 1-8 $\mu \mathrm{M}$. The most potent was the compound 106, characterized by a 1-(3-chlorophenyl)-3-methyl-2-pyrazolin-5-one moiety, with an $\mathrm{IC}_{50}$ value of $1 \mu \mathrm{M}$. The SI ratio $\left(\mathrm{IC}_{50} \mathrm{COX}-1 / \mathrm{IC}_{50} \mathrm{COX}-2\right.$ ) revealed compound $\mathbf{1 0 6}$ as selective for COX-2 (SI =7), compared with compounds $\mathbf{1 0 6 , 1 0 4 a , b , ~ a n d ~ 1 0 5 , ~ w h i c h ~ w e r e ~ n o n - ~}$ selective. In addition, docking studies highlighted a well-docked pose in the COX-2 active site showing H-bond and hydrophobic interactions. Surprisingly, compound 106 also decreased formalin-induced analgesia by $69 \%$.

$\mathrm{N}$-Acylethanolamine acid amidase (NAAA) is a lysosomal hydrolase that catalyzes the degradation of $\mathrm{N}$-acylethanolamines into fatty acids and ethanolamine in 
animal tissues. Its inhibition is a therapeutic tool in several pathophysiological conditions, such as inflammation and immune disorders, as well as pain. In 2019, Zhou et al. [77] synthesized a new series of pyrrolidine amide derivatives as antiinflammatory agents and tested their selectivity towards NAAA and fatty acid amide hydrolase (FAAH), using rat NAAA (rNAAA) and rat FAAH (rFAAH) as animal model. The starting idea was to modify the linker chain and the terminal phenyl group of compounds 107 and 108 (Fig. 22), which were previously described as potent NAAA inhibitors $\left(\mathrm{IC}_{50}=12.8\right.$ and $2.1 \mu \mathrm{M}$, respectively). The most active compounds were 109a, $\left(\mathrm{IC}_{50}=0.5 \mu \mathrm{M}\right) 109 \mathrm{~b}\left(\mathrm{IC}_{50}=0.7 \mu \mathrm{M}\right), 110\left(\mathrm{IC}_{50}=0.48 \mu \mathrm{M}\right)$, and $111\left(\mathrm{IC}_{50}=1.5 \mu \mathrm{M}\right)$ (Fig. 22) showing good NAAA inhibitory effects. Conversely, no relevant activity towards FAAH was found. Studies on the chemical space on compounds 107 and $\mathbf{1 0 8}$ indicated that the activity was lost upon substitution with $\mathrm{CH}_{3}, \mathrm{Cl}$, and $\mathrm{F}$ in position 2 of the terminal phenyl ring of parent 107. Instead, an improvement of activity was observed upon introduction of the same substituents at positions 3 or $4\left(\mathrm{IC}_{50} 3.7-9.6 \mu \mathrm{M}\right)$, except for the 4-Cl derivative $\left(\mathrm{IC}_{50} 34.5 \mu \mathrm{M}\right)$ (structures not shown). The same modifications on the terminal phenyl ring of compound 108 were detrimental for activity, most probably due to the conformationally restricted chain. Isosteric replacements of the distal phenyl ring with aromatic moieties such as 2-pyridyl, 3-pyridyl, 2-thienyl, and 3-thienyl, did not improve potency. This is in contrast to the introduction of a cyclohexyl ring as in compounds 109a
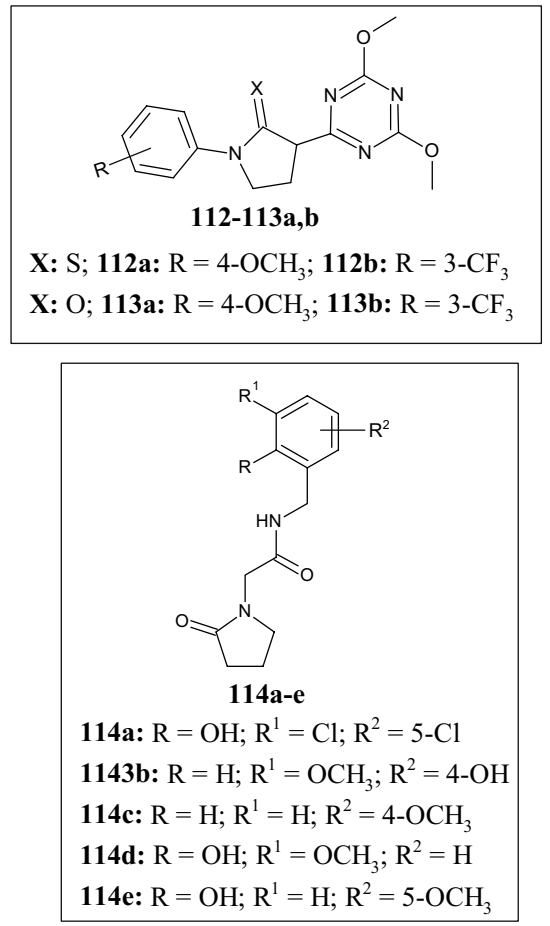

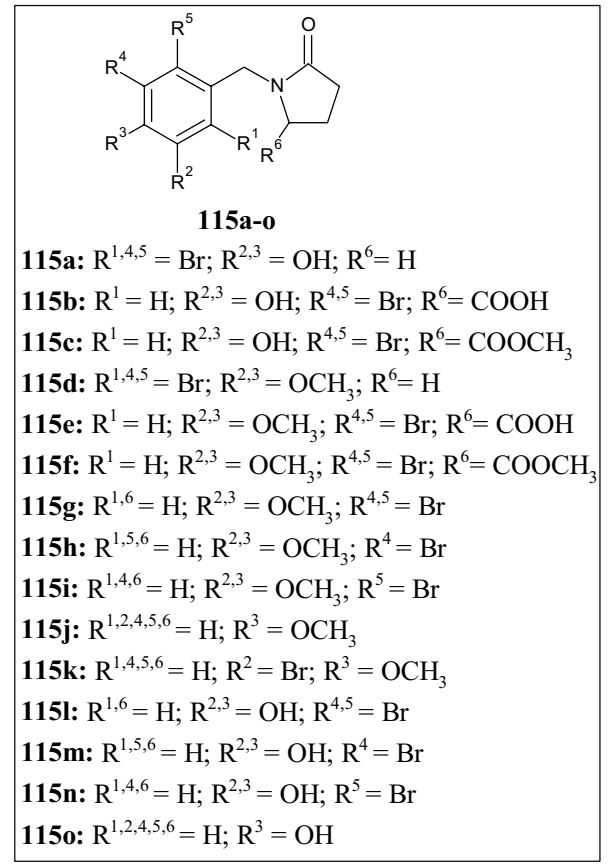

Fig. 23 Molecular structures of triazine-pyrrolidine-2-thiones 112a,b and pyrrolidin-2-ones 113a,b, pyrrolidin-2-ones 114a-e, and pyrrolidin-2-ones $\mathbf{1 1 5 a - 0}$ 
and $\mathbf{1 0 9 b}$, highlighting that (hetero)aromatic rings are less tolerated in the hydrophobic pocket of NAAA than aliphatic rings. Regarding the carbon chain between the pyrrolidine and the phenyl ring, the authors showed that flexible linkers led to a progressive increase in potency, except for compound 111, which was well suited to the hydrophobic pocket of NAAA. Molecular docking studies (PDB ID:6DY2) suggested that $\mathbf{1 1 1}$ may inhibit NAAA via a reversible and competitive inhibition mechanism.

As analogues of isoxazole compounds, in 2019 Lucescu et al. [78] synthesized and tested triazine-pyrrolidine-2-thiones 112a,b (Fig. 23) on the human protein farnesyltransferase (FTase). This protein catalyses the addition of a C15-farnesyl lipid group to the cysteine residue located in the carboxy-terminal tetrapeptide motif of a variety of important substrate proteins playing an important role in malignant transformations including proliferation, apoptosis, angiogenesis, and metastasis. Compound 112a showed good inhibitory activity toward the FTase enzyme with an $\mathrm{IC}_{50}$ of $3.82 \mu \mathrm{M}$, which was approximately 11 -fold lower than that of compound 112b $\left(\mathrm{IC}_{50}=41.06 \mu \mathrm{M}\right)$, highlighting the importance of the EWG on the phenyl ring. Interestingly, these two derivatives showed much better activity compared with the analogue in which pyrrolidine was replaced by the aromatic oxazole ring (structure not shown). In addition, the replacement of pyrrolidine-2-thione with pyrrolidin-2-one 113a,b (Fig. 23) did not affect activity toward the FTase protein.

The pyrrolidine-2-one scaffold is a structural feature recurrent in antitumor agents, as demonstrated by Kumar et al. [79] who synthesized the novel derivatives 114a-e (Fig. 23) by the reaction of substituted salicylaldehydes and 2-(2-oxopyrrolidin-1-yl)acetamide, leading to the respective Schiff base intermediates which were, in turn, reduced with sodium borohydride. Among all, compounds 114d and 114e showed the highest growth inhibition percentage against CCRF-CEM (acute lymphocytic leukemia) $(\mathbf{1 1 4 d}=73.15 \%)$ and NCI-H522 (non-small cell lung cancer) $(\mathbf{1 1 4} \mathbf{e}=41.8 \%)$ of the National Cancer Institute (NCI) panel. SAR analysis revealed that EWGs at positions 3 or 5 of the phenyl ring were unfavorable for antiproliferative activity compared with electron-donating methoxy groups. Hydroxy group introduction at position $2(\mathbf{1 1 4 d}$ and $\mathbf{1 1 4 e})$ led to an increase in antiproliferative activity compared with compounds $\mathbf{1 1 4 b}$ and 114c. Docking analyses suggested binding to the podophyllotoxin pocket of the protein gamma tubulin (PDB ID: 1SA1) as a potential mechanism of action underlying the anticancer activity.

The versatility of the pyrrolidine-2-one scaffold was demonstrated by Rezai et al. [80], who synthesized novel $N$-benzyl-2-pyrrolidone derivatives 115a-o (Fig. 23) as antioxidants and inhibitors of $\mathrm{AChE}$ and $\mathrm{BChE}$. $\mathrm{AChE}$ is an ubiquitous enzyme of the serine hydrolases class responsible for hydrolyzing the neurotransmitter acetylcholine, together with the homologous $\mathrm{BChE}$. $\mathrm{AD}$ is the most common form of dementia, characterized by loss of short-term memory, spatial disorientation, progressive loss of cognitive function, decreased intellect, and some other minor expressions. A common feature of the $\mathrm{AD}$ is the presence of $\mathrm{AChE}$, which is usually related to the $A \beta$ plaques and neurofibrillary tangles in the patient's brain. Recent findings suggested that both $\mathrm{A} \beta$ and abnormally hyperphosphorylated tau protein (P-tau) may influence the AChE expression with the development of a vicious cycle of $\mathrm{A} \beta$ and $\mathrm{P}$-tau dysregulation. In this context, $\mathrm{AChE}$ and $\mathrm{BChE}$ inhibitors can 

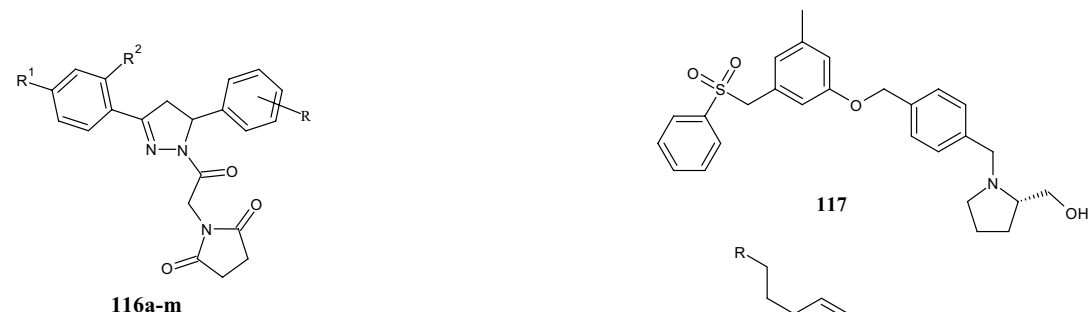

\footnotetext{
116a: $\mathrm{R}=-4-\mathrm{CH}_{3} ; \mathrm{R}^{1}=-\mathrm{H} ; \mathrm{R}^{2}=-\mathrm{H}$

116b: $\mathrm{R}=-4-\mathrm{CH}_{3} ; \mathrm{R}^{1}=-\mathrm{F} ; \mathrm{R}^{2}=-\mathrm{H}$

116c: $\mathrm{R}=-4-\mathrm{CH}_{3} ; \mathrm{R}^{1}=-\mathrm{F} ; \mathrm{R}^{2}=-\mathrm{F}$

116d: $R=-2$-furyl in place of phenyl; $R^{1}=-F ; R^{2}=-F$

116e: $\mathrm{R}=-2-\mathrm{Cl} ; \mathrm{R}^{1}=-\mathrm{H} ; \mathrm{R}^{2}=-\mathrm{H}$

116f: $\mathrm{R}=-\mathrm{H} ; \mathrm{R}^{1}=-\mathrm{H} ; \mathrm{R}^{2}=-\mathrm{H}$

116g: $\mathrm{R}=-4-\mathrm{F} ; \mathrm{R}^{1}=-\mathrm{H} ; \mathrm{R}^{2}=-\mathrm{H}$

116h: $\mathrm{R}=-\mathrm{H} ; \mathrm{R}^{1}=-\mathrm{F} ; \mathrm{R}^{2}=-\mathrm{H}$

116i: $R=-$ thiophen-2-yl in place of phenyl; $R^{1}=-H ; R^{2}=-H$

116j: $R=-2$-furyl in place of phenyl; $R^{1}=-H ; R^{2}=-H$

116k: $R=-2$-furyl in place of phenyl; $R^{1}=-F ; R^{2}=-H$

1161: $\mathrm{R}=-3,4-\mathrm{diOCH}_{3} ; \mathrm{R}^{1}=-\mathrm{F} ; \mathrm{R}^{2}=-\mathrm{F}$

116m: $\mathrm{R}=-3,4 \mathrm{diCl} ; \mathrm{R}^{1}=-\mathrm{H} ; \mathrm{R}^{2}=-\mathrm{H}$
}

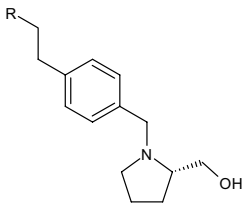

118: $R=-$ decyl

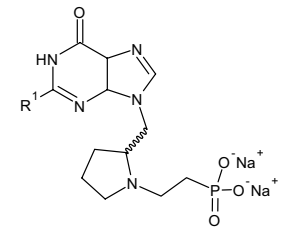

119-120a,b

(R)-119a: $\mathrm{R}^{1}=-\mathrm{NH}_{2}$

(S)-120a: $\mathrm{R}^{1}=-\mathrm{NH}_{2}$

(R)-119b: $\mathrm{R}^{1}=-\mathrm{H}$

(S)-120b: $\mathrm{R}^{1}=-\mathrm{H}$

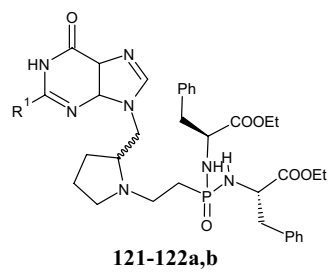

(R)-121a: $\mathrm{R}^{1}=-\mathrm{NH}_{2}$ (S)-122a: $\mathrm{R}^{1}=-\mathrm{NH}_{2}$ (R)-121b: $\mathrm{R}^{1}=-\mathrm{H}$

(S)-122b: $\mathrm{R}^{1}=-\mathrm{H}$
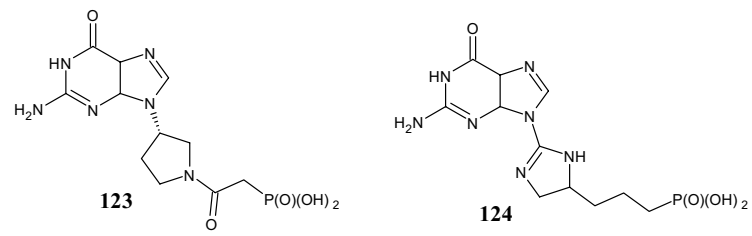

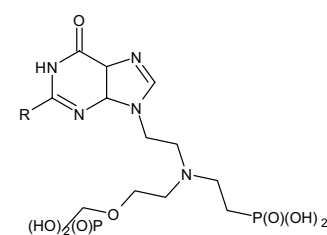

125a-b

125a: $\mathrm{R}=\mathrm{NH}_{2}$

125b: $R=-H$

Fig. 24 Molecular structures of hybrid pyrrolidine-2,5-diones 116a-m, 2-(hydroxymethyl)pyrrolidines 117 and 118, pyrrolidine phosphonates $119,120 a, b$, and phosphoramidate prodrugs $\mathbf{1 2 1 , 1 2 2 a , b}$

improve the cholinergic transmission, but with modest and temporary therapeutic effects. All compounds synthesized by the authors were able to inhibit the AChE enzyme at low nanomolar concentrations, with $K_{\mathrm{i}}$ values in the range of 2.60 and 
$16.36 \mathrm{nM}$. The most powerful AChE inhibitor was compound $\mathbf{1 1 5 f}$ with a $K_{\mathrm{i}}$ value of $2.60 \mathrm{nM}$. Furthermore, all compounds inhibited BChE with $K_{\mathrm{i}}$ values in the range of 13.10 and $54.47 \mathrm{nM}$. Measuring the DPPH radical scavenging activity, com-

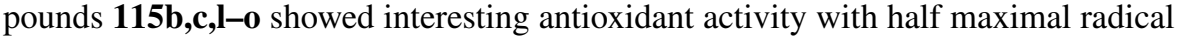
scavenging concentrations $\left(\mathrm{IC}_{50} \mu \mathrm{g} / \mathrm{ml}\right)$ in the range of 4.71 and 53.30. The radical scavenger activity is affected by the phenolic fraction and varies according to the number and position of the hydroxy groups.

To escape the problem of drug resistance, Tilekar et al. [81] recently published new pyrazoline-substituted pyrrolidine-2,5-dione hybrids 116a-m (Fig. 24), with anticancer activity against MCF7, HT29, and K562 cancer cells. Compounds $116 \mathbf{b}, \mathbf{f}, \mathbf{g}$, showed nanomolar activity against $\mathrm{MCF} 7$ with $\mathrm{IC}_{50}$ values in the range of 0.42 and $0.78 \mu \mathrm{M}$. Compounds $\mathbf{1 1 6 b}$ and $\mathbf{1 1 6 m}$ showed also activity in the submicromolar range against $\mathrm{HT} 29$ cells $\left(\mathrm{IC}_{50} 0.92 \mu \mathrm{M}\right.$ and $0.39 \mu \mathrm{M}$, respectively). The cytotoxicity assay against $\mathrm{K} 562$ revealed that compounds $\mathbf{1 1 6 a}$ and $\mathbf{1 1 6 g}\left(\mathrm{IC}_{50} 24.74\right.$ and $31.56 \mu \mathrm{M}$, respectively) were more potent than the reference compound pioglitazone ( $\left.\mathrm{IC}_{50} 40.3 \mu \mathrm{M}\right)$. Further studies with compound $\mathbf{1 1 6} \mathbf{b}$ demonstrated its ability to reduce the cell population in the G2/M phase and increase the cell population in the $\mathrm{G} 0 / \mathrm{G} 1$ phase, as well as inhibition of the anti-apoptotic protein Bcl-2 in a dose-dependent manner.

To obtain potent dual sphingosine kinase 1/2 (SphK1/SphK2) inhibitors, Li et al. [82] synthesized a series of 2-(hydroxymethyl)pyrrolidines, based on SAR investigation of potent and selective inhibitors previously reported in the literature (compound 117, SphK1-selective inhibitor) (Fig. 24). These enzymes are involved in the production of sphingosine 1-phosphate (S1P) from sphingosine and ATP, in a signalling pathway that is involved in cancer progression and immune cell chemiotaxis. While the 2-(hydroxymethyl)pyrrolidine scaffold is essential for hydrogen bonding with Asp178 in the binding pocket of SphK1, alteration of the aryl sulphonyl moiety changes the selectivity for SphK1 and SphK2. In this regard, the authors introduced various lipophilic substituents (i.e., alkyl, aryl, alkoxy, etc.) to the scaffold of compound 117 in place of the aryl sulphonyl moiety to mimic the sphingosine substrate of SphK1 and SphK2. The dodecyl analogue 118 proved to be the most potent dual SphK1/SphK2 inhibitor $\left(\mathrm{SphK} 1 K_{\mathrm{i}}=0.679 \mu \mathrm{M}\right.$, SphK2 $\left.K_{\mathrm{i}}=0.951 \mu \mathrm{M}\right)$ compared with derivatives with a shorter alkyl tail. On the other hand, the diaryl ether, alkoxy, alkenyl, alkynyl analogues (structures not shown) showed no improvement in biological activity. Molecular docking studies highlighted that compound 118 fitted in the Sph binding pocket of SphK1 establishing hydrogen bonding of the 2-(hydroxymethyl)pyrrolidine moiety. Specifically, (1) the primary alcohol hydrogen bonded with Ser168 and (2) the tertiary nitrogen hydrogen bonded with Asp178. Similarly, hydrogen bonds between the pyrrolidine nitrogen and Asp308 as well as the hydroxyl group and Ser298 were observed in the homology model of SphK2 docked with 118. The aliphatic dodecyl alkyl tail of compound 118 acquires a specific "J-shape", generating hydrophobic interactions within the binding pocket of the enzyme.

Recently, Frydrych et al. [83] used commercially available D- and L-prolinol as the starting material for the synthesis of novel antimalarial agents, yielding new chiral compounds in which a pyrrolidine ring is incorporated in the linker connecting the 
purine base to the phosphonate group(s) (119a,b and 120a,b) (Fig. 24). Compounds 119a,b and 120a,b were evaluated as inhibitors of the plasmodial hypoxanthine-guanine-(xanthine)-phosphoribosyltransferase [HG(X)PRT] of Plasmodium falciparum, $P$. vivax (HGPRT) and human HGPRT, and the results were compared with those of the previously published inhibitors 123, 124, 125a,b (Fig. 24). The biological results did not show an improvement in activity over compounds 123, 124, 125a,b. In fact, the new nucleotide analogues had $K_{\mathrm{i}}$ values in the range between 9 and $>50 \mathrm{mM}$ for human HGPRT, 5-44 mM for PfHGXPRT and between 20 and $>50 \mathrm{mM}$ for $P v H G-$ PRT, despite the increased flexibility achieved by the implementation of a $\mathrm{CH}_{2}$ group between the nucleobase and the pyrrolidine ring, which allows a free rotation. The same results were obtained when replacing the pyrrolidine nucleus with a six membered-ring, such as piperidine or piperazine (structures not showed). However, the phosphoramidate prodrugs 121a,b and 122a,b (Fig. 24), exhibited good antimalarial activity in a $P$. falciparum-infected human erythrocyte assay. In particular, the bisphosphoramidate prodrug 122a was potent $\left(\mathrm{IC}_{50}=2.5 \mu \mathrm{M}\right)$ against the chloroquine resistant $P$. falciparum $\mathrm{W} 2$ strain, with low cytotoxicity in human hepatocellular liver carcinoma (HepG2) and normal human dermal fibroblasts (NHDF) cell lines at a concentration of $100 \mu \mathrm{M}$.

\section{Concluding Remarks}

The present review is intended to provide significant support to medicinal chemists in the discovery of new biologically active pyrrolidine derivatives, providing a general overview of recent research concerning this scaffold, offering quick identification of the best synthetic route to apply. From this work, pyrrolidine emerges as a versatile scaffold found in molecules that exhibit a broad spectrum of biological activities. Pyrrolidines are useful to build compounds for fighting cancer and microbial infections, for metabolic diseases, as agents active in the CNS and for neurodegenerative diseases and immune disorders. Since three-dimensionality is an essential element of ligand-target interactions, the stereocenters present in pyrrolidine scaffolds would allow medicinal chemists to develop molecules with the most suitable configurations to fit into the ligand binding site of a target protein. In order to discover structurally novel compounds, the scaffold hopping strategy could be applied to the pyrrolidine core while maintaining its stereochemistry, together with exploration of the SAR of the most active pyrrolidine derivatives. We believe that the chemical versatility of the pyrrolidine nucleus and its ability to generate structural diversity could be essential to establish the clinical success of new bioactive molecules.

Funding Open access funding provided by Università degli Studi di Palermo within the CRUI-CARE Agreement. No funding was received to assist with the preparation of this manuscript.

\section{Declarations}

Conflict of Interest The authors declare that they have no known competing financial interests or personal relationships that could have appeared to influence the work reported in this paper. 
Open Access This article is licensed under a Creative Commons Attribution 4.0 International License, which permits use, sharing, adaptation, distribution and reproduction in any medium or format, as long as you give appropriate credit to the original author(s) and the source, provide a link to the Creative Commons licence, and indicate if changes were made. The images or other third party material in this article are included in the article's Creative Commons licence, unless indicated otherwise in a credit line to the material. If material is not included in the article's Creative Commons licence and your intended use is not permitted by statutory regulation or exceeds the permitted use, you will need to obtain permission directly from the copyright holder. To view a copy of this licence, visit http://creativecommons.org/licen ses/by/4.0/.

\section{References}

1. Raimondi MV, Presentato A, Li Petri G et al (2020) New synthetic nitro-pyrrolomycins as promising antibacterial and anticancer agents. Antibiotics 9:292. https://doi.org/10.3390/antibiotic s9060292

2. Raimondi MV, Listro R, Cusimano MG et al (2019) Pyrrolomycins as antimicrobial agents. Microwave-assisted organic synthesis and insights into their antimicrobial mechanism of action. Bioorg Med Chem 27:721-728. https://doi.org/10.1016/j.bmc.2019.01.010

3. Spanò V, Rocca R, Barreca M et al (2020) Pyrrolo[2',3':3,4]cyclohepta[1,2-d][1,2]oxazoles, a new class of antimitotic agents active against multiple malignant cell types. J Med Chem 63:12023-12042. https://doi.org/10.1021/acs.jmedchem.0c01315

4. Cascioferro S, Maggio B, Raffa D et al (2016) A new class of phenylhydrazinylidene derivatives as inhibitors of Staphylococcus aureus biofilm formation. Med Chem Res 25:870-878. https:// doi.org/10.1007/s00044-016-1535-9

5. Whatmore JL, Swann E, Barraja P et al (2002) Comparative study of isoflavone, quinoxaline and oxindole families of anti-angiogenic agents. Angiogenesis 5:45-51. https://doi.org/10.1023/a: 1021528628524

6. Jampilek J (2019) Heterocycles in medicinal chemistry. Molecules. https://doi.org/10.3390/ molecules 24213839

7. Gomtsyan A (2012) Heterocycles in drugs and drug discovery. Chem Heterocycl Comp 48:7-10. https://doi.org/10.1007/s10593-012-0960-z

8. Brown DG, Boström J (2016) Analysis of past and present synthetic methodologies on medicinal chemistry: where have all the new reactions gone? J Med Chem 59:4443-4458. https://doi.org/ 10.1021/acs.jmedchem.5b01409

9. Everett SA, Naylor MA, Barraja P et al (2001) Controlling the rates of reductively-activated elimination from the (indol-3-yl)methyl position of indolequinones. J Chem Soc Perkin Trans 2:843-860. https://doi.org/10.1039/B009652K

10. Clemons PA, Wilson JA, Dančík V et al (2011) Quantifying structure and performance diversity for sets of small molecules comprising small-molecule screening collections. Proc Natl Acad Sci USA 108:6817-6822. https://doi.org/10.1073/pnas.1015024108

11. Lovering F, Bikker J, Humblet C (2009) Escape from flatland: increasing saturation as an approach to improving clinical success. J Med Chem 52:6752-6756. https://doi.org/10.1021/ jm901241e

12. Aldeghi M, Malhotra S, Selwood DL, Chan AWE (2014) Two- and three-dimensional rings in drugs. Chem Biol Drug Des 83:450-461. https://doi.org/10.1111/cbdd.12260

13. Ritchie TJ, Macdonald SJF, Peace S et al (2012) The developability of heteroaromatic and heteroaliphatic rings - do some have a better pedigree as potential drug molecules than others? Med Chem Commun 3:1062-1069. https://doi.org/10.1039/C2MD20111A

14. Goldberg FW, Kettle JG, Kogej T et al (2015) Designing novel building blocks is an overlooked strategy to improve compound quality. Drug Discov Today 20:11-17. https://doi.org/10.1016/j. drudis.2014.09.023

15. Tajabadi FM, Campitelli MR, Quinn RJ (2013) Scaffold flatness: reversing the trend. Springer Sci Rev 1:141-151. https://doi.org/10.1007/s40362-013-0014-7

16. Maier ME (2015) Design and synthesis of analogues of natural products. Org Biomol Chem 13:5302-5343. https://doi.org/10.1039/C5OB00169B 
17. Liu XC, Lai D, Liu QZ et al (2016) Bioactivities of a new pyrrolidine alkaloid from the root barks of Orixa japonica. Molecules. https://doi.org/10.3390/molecules21121665

18. Carroll FI (2009) Epibatidine analogs synthesized for characterization of nicotinic pharmacophores-a review. Heterocycles 79:99-120

19. Islam MT, Mubarak MS (2020) Pyrrolidine alkaloids and their promises in pharmacotherapy. Adv Tradit Med 20:13-22. https://doi.org/10.1007/s13596-019-00419-4

20. Bhat C, Tilve SG (2014) Recent advances in the synthesis of naturally occurring pyrrolidines, pyrrolizidines and indolizidine alkaloids using proline as a unique chiral synthon. RSC Adv 4:54055452. https://doi.org/10.1039/C3RA44193H

21. Vitaku E, Smith DT, Njardarson JT (2014) Analysis of the structural diversity, substitution patterns, and frequency of nitrogen heterocycles among US FDA Approved Pharmaceuticals. J Med Chem 57:10257-10274. https://doi.org/10.1021/jm501100b

22. Dalko PI, Moisan L (2004) In the golden age of organocatalysis. Angew Chem Int Ed 43:51385175. https://doi.org/10.1002/anie.200400650

23. Higashiyama K, Inoue $\mathrm{H}$, Takahashi H (1994) Diastereoselective addition of chiral imines and 1,3-oxazolidines with grignard reagents; asymmetric synthesis of (R)-2-aryl- and (R, R)2,5-bis(aryl)pyrrolidines. Tetrahedron 50:1083-1092. https://doi.org/10.1016/S0040-4020(01) 80819-X

24. Llopis S, García T, Cantín Á et al (2018) Chiral hybrid materials based on pyrrolidine building units to perform asymmetric Michael additions with high stereocontrol. Catal Sci Technol 8:5835-5847. https://doi.org/10.1039/C8CY01650J

25. Henary M, Kananda C, Rotolo L et al (2020) Benefits and applications of microwave-assisted synthesis of nitrogen containing heterocycles in medicinal chemistry. RSC Adv 10:14170-14197. https://doi.org/10.1039/D0RA01378A

26. Li Petri G, Spanò V, Spatola R et al (2020) Bioactive pyrrole-based compounds with target selectivity. Eur J Med Chem 208:112783. https://doi.org/10.1016/j.ejmech.2020.112783

27. Cascioferro S, Raimondi MV, Cusimano MG et al (2015) Pharmaceutical potential of synthetic and natural pyrrolomycins. Molecules 20:21658-21671. https://doi.org/10.3390/molecules201219797

28. Raimondi MV, Schillaci D, Petruso S (2007) Synthesis and anti-staphylococcal activity of new halogenated pyrroles related to Pyrrolomycins F. J Heterocycl Chem 44:1407-1411. https://doi.org/10. 1002/jhet.5570440626

29. Adrio J, Carretero JC (2019) Stereochemical diversity in pyrrolidine synthesis by catalytic asymmetric 1,3-dipolar cycloaddition of azomethine ylides. Chem Commun 55:11979-11991. https:// doi.org/10.1039/C9CC05238K

30. Biswas AK, Johnson DG (2012) Transcriptional and nontranscriptional functions of E2F1 in response to DNA damage. Cancer Res 72:13-17. https://doi.org/10.1158/0008-5472.CAN-11-2196

31. Gupta MR, Thakur K, Khare NK (2018) L-Proline/ $\mathrm{CeCl}_{3} \cdot 7 \mathrm{H}_{2} \mathrm{O}-\mathrm{NaI}$ mediated stereoselective synthesis of $\alpha$-2-deoxy glycosides from glucal. Carbohydr Res 457:51-55. https://doi.org/10.1016/j. carres.2018.01.003

32. Brooks WH, Guida WC, Daniel KG (2011) The significance of chirality in drug design and development. Curr Top Med Chem 11:760-770. https://doi.org/10.2174/156802611795165098

33. Kunitski M, Riehn C, Matylitsky V et al (2010) Pseudorotation in pyrrolidine: rotational coherence spectroscopy and ab initio calculations of a large amplitude intramolecular motion. Phys Chem Chem Phys 12:72-81. https://doi.org/10.1039/B917362E

34. Galloway WRJD, Isidro-Llobet A, Spring DR (2010) Diversity-oriented synthesis as a tool for the discovery of novel biologically active small molecules. Nat Commun 1:80. https://doi.org/10.1038/ ncomms 1081

35. Kumar A, Gupta G, Srivastava S (2010) Diversity oriented synthesis of pyrrolidines via natural carbohydrate solid acid catalyst. J Comb Chem 12:458-462. https://doi.org/10.1021/cc100007a

36. Koskinen AMP, Helaja J, Kumpulainen ETT et al (2005) Locked conformations for proline pyrrolidine ring: synthesis and conformational analysis of cis- and trans-4-tert-butylprolines. J Org Chem 70:6447-6453. https://doi.org/10.1021/jo050838a

37. Jurica EA, Wu X, Williams KN et al (2017) Discovery of pyrrolidine-containing GPR40 agonists: stereochemistry effects a change in binding mode. J Med Chem 60:1417-1431. https://doi.org/10. 1021/acs.jmedchem.6b01559

38. Luxenburger A, Schmidt D, Ianes C et al (2019) Design, synthesis and biological evaluation of isoxazole-based CK1 inhibitors modified with chiral pyrrolidine scaffolds. Molecules 24:873. https:// doi.org/10.3390/molecules 24050873 
39. Fanning SW, Hodges-Gallagher L, Myles DC et al (2018) Specific stereochemistry of OP-1074 disrupts estrogen receptor alpha helix 12 and confers pure antiestrogenic activity. Nat Commun 9:2368. https://doi.org/10.1038/s41467-018-04413-3

40. Jiang B, Duan JJ-W, Stachura S et al (2020) Discovery of (3S,4S)-3-methyl-3-(4-fluorophenyl)-4-(4(1,1,1,3,3,3-hexafluoro-2-hydroxyprop-2-yl)phenyl)pyrrolidines as novel ROR $\gamma \mathrm{t}$ inverse agonists. Bioorg Med Chem Lett 30:127392. https://doi.org/10.1016/j.bmcl.2020.127392

41. An F, Maji B, Min E et al (2020) Basicities and nucleophilicities of pyrrolidines and imidazolidinones used as organocatalysts. J Am Chem Soc 142:1526-1547. https://doi.org/10.1021/jacs.9b118 77

42. Breugst M, Reissig H-U (2020) The Huisgen reaction: milestones of the 1,3-dipolar cycloaddition. Angew Chem Int Ed 59:12293-12307. https://doi.org/10.1002/anie.202003115

43. Maiuolo L, Algieri V, Olivito F, De Nino A (2020) Recent developments on 1,3-dipolar cycloaddition reactions by catalysis in green solvents. Catalysts 10:65. https://doi.org/10.3390/catal10010065

44. Coldham I, Hufton R (2005) Intramolecular dipolar cycloaddition reactions of azomethine ylides. Chem Rev 105:2765-2810. https://doi.org/10.1021/cr040004c

45. Min R, Wu W, Wang M et al (2019) Discovery of 2-(1-(3-(4-Chloroxyphenyl)-3-oxo- propyl)pyrrolidine-3-yl)-1H-benzo[d]imidazole-4-carboxamide: a potent poly(ADP-ribose) polymerase (PARP) inhibitor for treatment of cancer. Molecules 24:1901. https://doi.org/10.3390/molecules24101901

46. Wang Y, Zhao H, Brewer JT et al (2018) De Novo design, synthesis, and biological evaluation of 3,4-disubstituted pyrrolidine sulfonamides as potent and selective glycine transporter 1 competitive inhibitors. J Med Chem 61:7486-7502. https://doi.org/10.1021/acs.jmedchem.8b00295

47. Zhang H, Ding CZ, Lai Z et al (2015) Synthesis and biological evaluation of novel pyrrolidine acid analogs as potent dual PPAR $\alpha / \gamma$ agonists. Bioorg Med Chem Lett 25:1196-1205. https://doi.org/10. 1016/j.bmcl.2015.01.066

48. Periyasami G, Kamalraj S, Padmanaban R et al (2019) Glucosamine-6-phosphate synthase inhibiting C3- $\beta$-cholesterol tethered spiro heterocyclic conjugates: synthesis and their insight of DFT and docking study. Bioorg Chem 88:102920. https://doi.org/10.1016/j.bioorg.2019.102920

49. Shyamsivappan S, Saravanan A, Vivek R et al (2020) Novel phenyl and thiophene dispiro indenoquinoxaline pyrrolidine quinolones induced apoptosis via G1/S and G2/M phase cell cycle arrest in MCF-7 cells. New J Chem 44:15031-15045. https://doi.org/10.1039/D0NJ02588G

50. Benabdallah M, Talhi O, Nouali F et al (2018) Advances in spirocyclic hybrids: chemistry and medicinal actions. Curr Med Chem 25:3748-3767. https://doi.org/10.2174/09298673256661803091 24821

51. Hati S, Tripathy S, Dutta PK et al (2016) Spiro[pyrrolidine-3, 3'-oxindole] as potent anti-breast cancer compounds: their design, synthesis, biological evaluation and cellular target identification. Sci Rep 6:1-10. https://doi.org/10.1038/srep32213

52. Guazzelli L, D’Andrea F, Sartini S et al (2019) Synthesis and investigation of polyhydroxylated pyrrolidine derivatives as novel chemotypes showing dual activity as glucosidase and aldose reductase inhibitors. Bioorg Chem 92:103298. https://doi.org/10.1016/j.bioorg.2019.103298

53. Li Z, Wang X, Lin Y et al (2020) Design, synthesis, and evaluation of pyrrolidine based CXCR4 antagonists with in vivo anti-tumor metastatic activity. Eur J Med Chem 205:112537. https://doi. org/10.1016/j.ejmech.2020.112537

54. da Silva EC, Yamakawa NCG, Santos AAD, Coelho F (2017) Short and diastereoselective total synthesis of the polyhydroxylated pyrrolidine LAB-1: a potent $\alpha$-glycosidase inhibitor. Synth 49:48694875. https://doi.org/10.1055/s-0036-1590799

55. Debbabi KF, Al-Harbi SA, Al-Saidi HM et al (2016) Study of reactivity of cyanoacetohydrazonoethyl- $N$-ethyl- $N$-methyl benzenesulfonamide: preparation of novel anticancer and antimicrobial active heterocyclic benzenesulfonamide derivatives and their molecular docking against dihydrofolate reductase. J Enzym Inhib Med Ch 31:7-19. https://doi.org/10.1080/14756366.2016.1217851

56. Rybka S, Obniska J, Rapacz A et al (2017) Synthesis and evaluation of anticonvulsant properties of new $N$-Mannich bases derived from pyrrolidine-2,5-dione and its 3-methyl-, 3-isopropyl, and 3-benzhydryl analogs. Bioorg Med Chem Lett 27:1412-1415. https://doi.org/10.1016/j.bmcl.2017.02.002

57. Rybka S, Obniska J, Żmudzki P et al (2017) Synthesis and determination of lipophilicity, anticonvulsant activity, and preliminary safety of 3-substituted and 3-unsubstituted $N$-[(4-arylpiperazin1-yl)alkyl]pyrrolidine-2,5-dione derivatives. ChemMedChem 12:1848-1856. https://doi.org/10. $1002 /$ cmdc. 201700539 
58. Góra M, Czopek A, Rapacz A et al (2020) Synthesis, anticonvulsant and antinociceptive activity of new hybrid compounds: derivatives of 3-(3-methylthiophen-2-yl)-pyrrolidine-2,5-dione. Int J Mol Sci 21:5750. https://doi.org/10.3390/ijms21165750

59. Obniska J, Góra M, Rapacz A et al (2021) Synthesis, anticonvulsant, and antinociceptive activity of new 3-(3-methyl-2,5-dioxo-3-phenylpyrrolidin-1-yl)propanamides and 3-phenyl-butanamides. Arch Pharm (Weinheim) 354:e2000225. https://doi.org/10.1002/ardp.202000225

60. Góra M, Czopek A, Rapacz A et al (2021) Design, synthesis and biological activity of new amides derived from 3-benzhydryl and 3-sec-butyl-2,5-dioxo-pyrrolidin-1-yl-acetic acid. ChemMedChem 16:1619-1630. https://doi.org/10.1002/cmdc.202001007

61. Oktay K, Kose L, Şendil K et al (2017) Synthesis of 3-chloro-1-substituted aryl pyrrolidine-2,5-dione derivatives: discovery of potent human carbonic anhydrase inhibitors. Med Chem Res. https:// doi.org/10.1007/s00044-017-1865-2

62. Jan MS, Ahmad S, Hussain F et al (2020) Design, synthesis, in-vitro, in-vivo and in-silico studies of pyrrolidine-2,5-dione derivatives as multitarget anti-inflammatory agents. Eur J Med Chem 186:111863. https://doi.org/10.1016/j.ejmech.2019.111863

63. Gouda AM, Ali HI, Almalki WH et al (2016) Design, synthesis, and biological evaluation of some novel pyrrolizine derivatives as COX inhibitors with anti-inflammatory/analgesic activities and low ulcerogenic liability. Molecules 21:201. https://doi.org/10.3390/molecules21020201

64. Pannala P, Reddy P, Misra S et al (2017) Synthesis, molecular docking, in vitro antiproliferative and antioxidant activity of novel pyrrolidinyl-carbazole derivatives. Curr Org Synth 14:11721179. https://doi.org/10.2174/1570179414666170606120934

65. Aboul-Enein M, El-Azzouny AAE-S, Saleh OA et al (2016) Synthesis, bio-evaluation and molecular modeling studies of (2S)-1-[(\{[1-substituted cyclohexyl] methyl $\}$ amino) acetyl] pyrrolidine-2-carbonitriles for their DPP-4 inhibiting activity. Int J Pharm Sci Rev Res 39:230-240 (scopus ID: 19700188319)

66. Wan Y, Wang J, Sun F et al (2015) Design, synthesis and preliminary biological studies of pyrrolidine derivatives as Mcl-1 inhibitors. Bioorg Med Chem 23:7685-7693. https://doi.org/10. 1016/j.bmc.2015.11.014

67. Gerokonstantis DT, Nikolaou A, Magkrioti C et al (2020) Synthesis of novel 2-pyrrolidinone and pyrrolidine derivatives and study of their inhibitory activity against autotaxin enzyme. Bioorg Med Chem 28:115216. https://doi.org/10.1016/j.bmc.2019.115216

68. Odusami JA, Ikhile MI, Izunobi JU et al (2020) Synthesis of substituted N-(2'-nitrophenyl) pyrrolidine-2-carboxamides towards the design of proline-rich antimicrobial peptide mimics to eliminate bacterial resistance to antibiotics. Bioorg Chem 105:104340. https://doi.org/10.1016/j. bioorg.2020.104340

69. De Tran Q, Bepary S, Lee GH et al (2016) Synthesis of (3S,4S)-4-aminopyrrolidine-3-ol derivatives and biological evaluation for their BACE1 inhibitory activities. Bioorg Med Chem Lett 26:51-54. https://doi.org/10.1016/j.bmcl.2015.11.033

70. Choubey PK, Tripathi A, Sharma P, Shrivastava SK (2020) Design, synthesis, and multitargeted profiling of N-benzylpyrrolidine derivatives for the treatment of Alzheimer's disease. Bioorg Med Chem 28:115721. https://doi.org/10.1016/j.bmc.2020.115721

71. Bashandy M, El-Gilil S (2016) Synthesis, molecular docking and antihuman breast cancer activities of novel thiazolyl acetonitriles and thiazolyl acrylonitriles and their derivatives containing benzenesulfonylpyrrolidine moiety. Heterocycles 92:431-469. https://doi.org/10.3987/ COM-15-13384

72. Hassan AHE, Park HR, Yoon YM et al (2019) Antiproliferative 3-deoxysphingomyelin analogs: design, synthesis, biological evaluation and molecular docking of pyrrolidine-based 3-deoxysphingomyelin analogs as anticancer agents. Bioorg Chem 84:444-455. https://doi.org/10. 1016/j.bioorg.2018.11.040

73. Zhang H, Wang X, Mao J et al (2018) Synthesis and biological evaluation of novel benzofuroxan-based pyrrolidine hydroxamates as matrix metalloproteinase inhibitors with nitric oxide releasing activity. Bioorg Med Chem 26:4363-4374. https://doi.org/10.1016/j.bmc.2018.06.023

74. Asano M, Hitaka T, Imada $T$ et al (2017) Synthesis and biological evaluation of novel selective androgen receptor modulators (SARMs). Part II: Optimization of 4-(pyrrolidin-1-yl)benzonitrile derivatives. Bioorg Med Chem Lett 27:1897-1901. https://doi.org/10.1016/j.bmcl.2017.03.038

75. Aikawa K, Miyawaki T, Hitaka T et al (2015) Synthesis and biological evaluation of novel selective androgen receptor modulators (SARMs). Part I. Bioorg Med Chem 23:2568-2578. https:// doi.org/10.1016/j.bmc.2015.03.032 
76. Kaur S, Kumari P, Singh G et al (2018) Design and synthesis of aza-/oxa heterocycle-based conjugates as novel anti-inflammatory agents targeting cyclooxygenase-2. ACS Omega 3:58255845. https://doi.org/10.1021/acsomega.8b00445

77. Zhou P, Xiang L, Zhao D et al (2019) Synthesis, biological evaluation, and structure activity relationship (SAR) study of pyrrolidine amide derivatives as $N$-acylethanolamine acid amidase (NAAA) inhibitors. Med Chem Commun 10:252-262. https://doi.org/10.1039/C8MD00432C

78. Lucescu L, Ghinet A, Shova S et al (2019) Exploring isoxazoles and pyrrolidinones decorated with the 4,6-dimethoxy-1,3,5-triazine unit as human farnesyltransferase inhibitors. Arch Pharm 352:1800227. https://doi.org/10.1002/ardp.201800227

79. Kumar A, Singh UK, Muzaffar F et al (2018) Design, synthesis and anti-proliferative activity of noval 1,2,4-triazine and pyrrolidin-2-one derivatives. Der Pharma Chemica 10(1):124-131

80. Rezai M, Bayrak Ç, Taslimi P et al (2018) The first synthesis and antioxidant and anticholinergic activities of 1-(4,5-dihydroxybenzyl)pyrrolidin-2-one derivative bromophenols including natural products. Turk J Chem 42:808-825. https://doi.org/10.3906/kim-1709-34

81. Tilekar K, Upadhyay N, Meyer-Almes F-J et al (2020) Synthesis and biological evaluation of pyrazoline and pyrrolidine-2,5-dione hybrids as potential antitumor agents. ChemMedChem 15:18131825. https://doi.org/10.1002/cmdc.202000458

82. Li H, Sibley CD, Kharel Y et al (2021) Lipophilic tail modifications of 2-(hydroxymethyl)pyrrolidine scaffold reveal dual sphingosine kinase 1 and 2 inhibitors. Bioorg Med Chem 30:115941. https://doi.org/10.1016/j.bmc.2020.115941

83. Frydrych J, Keough DT, Chavchich M et al (2021) Nucleotide analogues containing a pyrrolidine, piperidine or piperazine ring: synthesis and evaluation of inhibition of plasmodial and human 6-oxopurine phosphoribosyltransferases and in vitro antimalarial activity. Eur J Med Chem 219:113416. https://doi.org/10.1016/j.ejmech.2021.113416

Publisher's Note Springer Nature remains neutral with regard to jurisdictional claims in published maps and institutional affiliations.

\section{Authors and Affiliations}

\section{Giovanna Li Petri ${ }^{1}$ Maria Valeria Raimondi ${ }^{1}\left[\begin{array}{l}\text { ( } \\ \text { Virginia Spanò }\end{array}{ }^{1} \cdot\right.$ Ralph Holl $^{2}$. Paola Barraja ${ }^{1} \cdot$ Alessandra Montalbano $^{1}$}

1 Department of Biological, Chemical and Pharmaceutical Sciences and Technologies (STEBICEF), University of Palermo, Via Archirafi 32, 90123 Palermo, Italy

2 Department of Chemistry, Institute of Organic Chemistry, University of Hamburg, Martin-Luther-King-Platz 6, 20146 Hamburg, Germany 